\title{
poly(UG)-tailed RNAs in Genome Protection and Epigenetic Inheritance
}

Aditi Shukla ${ }^{1,4}$, Jenny Yan ${ }^{1,4}$, Daniel J. Pagano ${ }^{1}$, Anne E. Dodson ${ }^{1}$, Yuhan Fei ${ }^{1,2}$, Josh Gorham $^{1}$, J.G. Seidman ${ }^{1}$, Marvin Wickens ${ }^{3}$, Scott Kennedy ${ }^{1 *}$

${ }^{1}$ Department of Genetics, Blavatnik Institute at Harvard Medical School, Boston, MA 02115, USA.

${ }^{2}$ College of Agriculture, Nanjing Agricultural University, Nanjing, Jiangsu, China. ${ }^{3}$ Department of Biochemistry, University of Wisconsin-Madison, Madison, WI 53706, USA. ${ }^{4}$ These authors contributed equally to this work.

* Corresponding author: kennedy@genetics.med.harvard.edu 


\begin{abstract}
Mobile genetic elements threaten genome integrity in all organisms. MUT-2/RDE-3 is a ribonucleotidyltransferase required for transposon silencing and RNA interference (RNAi) in C. elegans. When tethered to RNAs in heterologous expression systems, RDE-3 can add

5 long stretches of alternating non-templated uridine $(U)$ and guanosine $(G)$ ribonucleotides to the 3' termini of these RNAs (polyUG or pUG tails). Here, we show that, in its natural context in C. elegans, RDE-3 adds pUG tails to transposon RNAs, as well as to targets of RNAi. pUG tails with more than 16 perfectly alternating 3' $U$ and $G$ nucleotides convert otherwise inert RNA fragments into agents of gene silencing. pUG tails promote gene

10 silencing by recruiting RNA-dependent RNA Polymerases (RdRPs), which use pUG-tailed RNAs as templates to synthesize small interfering RNAs (siRNAs). Cycles of pUG RNAtemplated siRNA synthesis and siRNA-directed mRNA pUGylation underlie dsRNAdirected transgenerational epigenetic inheritance in the $C$. elegans germline. Our results show that pUG tails convert RNAs into transgenerational memories of past gene silencing 15 events, which, we speculate, allow parents to inoculate progeny against the expression of unwanted or parasitic genetic elements.
\end{abstract}




\section{Main text}

Transposable elements are mobile parasitic genetic elements present in all genomes. Transposons threaten genome integrity, and can cause disease by disrupting genes or inducing non-allelic recombination. RNA interference (RNAi) is a conserved gene silencing process initiated by double- stranded RNA (dsRNA) ${ }^{1}$. Forward genetic screens to identify factors required for either transposon silencing or RNAi have been conducted in the model metazoan C. elegans ${ }^{2-}$ ${ }^{4}$. These screens identified a similar set of genes, indicating that an RNAi-related process silences transposons ${ }^{2-4}$. One gene required for both efficient transposon silencing and RNAi in C. elegans

25 is mut-2/rde-3, which encodes a protein with homology to ribonucleotidyltransferases $(\mathrm{rNTs})^{2-5}$. rNTs add non-templated ribonucleotides to RNAs and other substrates ${ }^{6,7}$. Recently, C. elegans MUT-2/RDE-3 (henceforth, RDE-3) was shown to add perfectly alternating $U$ and $G$ ribonucleotides to the 3' termini of RNAs (termed polyUG or pUG tails) to which it was tethered in either S. cerevisiae or $X$. laevis oocytes ${ }^{8}$. These data suggest that RDE-3 may append non-

30 templated pUG tails to the 3' termini of RNAs during transposon silencing and/or RNAi in C. elegans.

RNAi directs RDE-3-dependent mRNA pUGylation. We first asked whether pUG tails are added to RNAs targeted by RNAi in C. elegans. We exposed animals to dsRNA targeting the germline-expressed gene oma-19. Total RNA was extracted and reverse transcribed (RT) using an $(\mathrm{AC})_{9}$ oligo, and nested PCR was used to try to detect oma-1 RNAs modified with 3' pUG repeats (Fig. 1a). This approach detected PCR products that were dependent on oma-1 dsRNA (Fig. 1b), as well as on components of the RNAi machinery including RDE-4, which promotes dsRNA processing into siRNAs ${ }^{10,11}$, the siRNA-binding Argonaute (AGO) protein RDE-1 ${ }^{10,11}$, and RDE-8, which is an endonuclease thought to cleave mRNAs exhibiting homology to siRNAs ${ }^{12}$ (Fig. 1c). 
Sanger and Illumina sequencing revealed that most $(>89 \%)$ pUG PCR products were derived from hybrid RNAs consisting of nearly perfectly alternating (error rate $<2 \%$, Table S1) U and $G$ nucleotide (nt) repeats appended to the 3' termini of sense and spliced oma-1 mRNA

45 fragments (Fig. 1d, e). Critically, most (64\%) pUG tails were longer (range=19-75nt) than the $(\mathrm{AC})_{9}$ oligo used for RT (Fig. 1d, Table S1), indicating that the pUG RNAs we detected were not the result of priming off genomically-encoded UG-rich sequences. Sequencing showed that pUG tails could be appended to any nucleotide of the oma-1 mRNA; however, if the last templated nucleotide of the oma-1 mRNA was a $G$ or $U$, then pUG tails tended to initiate with $U(96 \%)$ or $G$ 50 (88\%), respectively (Fig. 1f). RDE-3 was required for addition of pUG repeats to mRNA fragments (termed pUGylation): rde-3 mutants, including rde-3(ne3370) animals, which harbor a deletion that removes residues required for catalysis within the rNT domain of RDE-3 (henceforth rde-3() $)^{8}$, failed to produce oma-1 pUG RNAs in response to oma-1 dsRNA (Fig. 1b). pUGylation defects in rde-3 mutants were rescued by introducing a wild-type copy of $r d e-3$ into $r d e-3(-)$ animals or by

55 CRISPR/Cas9-mediated reversion of a missense allele (ne298) of rde-3 to wild-type (Fig. 1b). RNA pUGylation was a general response to RNAi: animals exposed to dsRNA targeting a germline-expressed $g f p:: h 2 b$ transgene or the hypodermally-expressed $d p y-11 \mathrm{mRNA}^{13}$ produced RDE-3-dependent gfp and $d p y-11$ pUG RNAs, respectively (Extended Data Fig. 1). Furthermore, pUGylation was sequence-specific, since $d p y-11$ dsRNA did not induce oma-1 pUG RNA biogenesis and vice versa (Extended Data Fig. 1). Together, these data indicate that RDE3 adds pUG tails to mRNAs targeted for silencing by RNAi.

pUG tails turn inert mRNA fragments into agents of gene silencing. Given that RNAi is a gene-silencing phenomenon ${ }^{1}$, pUG tails could either mark mRNA fragments for degradation 65 or convert mRNA fragments into active mediators of gene silencing. To differentiate these possibilities, we asked whether in vitro transcribed pUG RNAs possessed gene silencing activity. 
Indeed, injection of a gfp pUG RNA, consisting of 18 3'terminal pUG repeats appended to the first 369nts of the gfp mRNA, into animals expressing a germline-expressed $g f p:: h 2 b$ transgene was sufficient to silence $g f p:: h 2 b$ expression (Fig. 2a). The same gfp mRNA fragment without a 3' tail or with 18 3'-terminal pGC, pAC, or pAU repeats lacked gene silencing activity (Fig. 2a). Note: to control for potential dsRNA contamination in our in vitro transcription reactions, all RNAs were injected into rde-1(ne219) mutant animals, as rde-1 mutants cannot respond to dsRNA (Fig. 2a, b) $)^{4}$. The ability of a pUG tail to turn an mRNA fragment into an agent of gene silencing was both general and sequence-specific. oma-1(zu405ts) animals lay arrested embryos unless oma-

751 (zu405ts) is silenced ${ }^{14}$. An in vitro transcribed $541 \mathrm{nt}$ long oma-1 mRNA fragment modified with 18 3' pUG_but not 18 pGC, pAC, or pAU_repeats was capable of silencing oma-1(zu405ts) (Fig. 2b). Additionally, an oma-1 pUG RNA injection did not silence gfp::h2b and vice versa (Extended Data Fig. 2). We conclude that pUG tails convert otherwise inert mRNA fragments into agents of gene silencing.

We used the pUG RNA injection assay to define the features of pUG RNAs required for biological activity. We injected animals with oma-1 pUG RNAs harboring varying numbers of 3' UG repeats and found that 14,18 , or 40 -but not 1,5 , or 8 -UG repeats were capable of triggering oma-1 gene silencing when appended to the same oma-1 mRNA fragment (Fig. 2c). We also found that while pUG tails with perfectly alternating $U$ and $G$ nucleotide repeats conferred silencing activity to an mRNA fragment, 3' tails with scrambled UG sequence or other combinations of Us and Gs did not (Fig. 2c). Moreover, while an oma-1 mRNA fragment with a 3' pUG tail triggered oma-1(zu405ts) silencing, oma-1 mRNA fragments with 5 ' or internal UG repeats did not (Fig. 2c). Finally, the oma-1 segment of an oma-1 pUG RNA had to possess the sense coding sequence and be $>50$ nts in length for pUG RNA functionality (Extended Data Fig.

90 3). Together, these data show that a pUG RNA must consist of $>8$ 3' UG repeats appended to $>50$ nt of sense RNA in order to trigger gene silencing. 
RDE-3 pUGylates germline-expressed RNAs. We next asked whether endogenous mRNAs are pUGylated in C. elegans. In the absence of RDE-3, Tc1 transposase RNA is 95 upregulated and Tc1 mobilizes ${ }^{2}$, suggesting that the Tc1 RNA might be pUGylated. We tested this idea using a Tc1-specific pUG PCR assay (Fig. 1a) and observed RDE-3-dependent pUG tails appended to Tc1 RNA fragments, which were between 41-195nt in length (Fig. 3a and Table S1). In addition, Tc1 mobilization caused by rde-3 mutation was suppressed by injection of a Tc1 pUG RNA (Fig. 3b). We conclude that RDE-3-based pUGylation silences the Tc1 transposon in C. elegans.

To identify additional targets of pUGylation, we conducted mRNA-seq on wild-type and rde-3(-) animals and identified 346 RNAs that were upregulated in rde-3(-) animals (Table S2, adjusted $p$ value $<0.05$ and log2 fold change $>1.5$ ). We observed increased levels of Tc1 RNA, as well as six other DNA transposons (Tc1A, TC4, TC5, MIRAGE1, CEMUDR1, Chapaev-2), several LTR retrotransposons (CER3, CER9, CER13), and 294 predicted protein-coding RNAs (Table S2). Directed pUG RT-PCR analyses confirmed that Tc4v, Tc5, CER3, and four of five genes tested from amongst our list of top 25 most RDE-3-regulated mRNAs, were pUGylated in an RDE-3 dependent manner (Extended Data Fig. 4). pUG tails were not detected on RNAs whose expression is unchanged in rde-3 mutants, such as oma-1, gfp or dpy-11 (Extended Data Fig. 1) and two additional genes selected at random (Extended Data Fig. 4). We used CRISPR/Cas9 to introduce a gfp tag into one RDE-3-regulated and pUGylated locus, c38d9.2. We observed diffuse C38D9.2::GFP expression in the germline syncytium of $r d e-3(-)$, but not $r d e-$ $3(+)$, animals, confirming that $c 38 d 9.2$ is regulated by RDE-3 (and thus, pUGylation) and showing that this regulation occurs in the germline (Fig. 3c). We conclude that RDE-3 adds pUG tails to 115 endogenous RNAs in C. elegans, which include, but are not limited to, transposon RNAs.

pUG RNAs and germ granules. Germ granules are liquid-like condensates that form near the outer nuclear membrane in most animal germ cells ${ }^{15}$. Germ granules are thought to 
promote germ cell totipotency by concentrating germline determinants, which include maternal RNAs and proteins, into developing germline blastomeres ${ }^{15}$. C. elegans RDE-3 localizes to perinuclear germ granules termed Mutator foci ${ }^{16}$. RNA fluorescence in situ hybridization (RNA FISH) using a fluorescently labeled $p(A C)_{9}$ probe to detect pUG RNAs (pUG FISH) showed that pUG RNAs localized to perinuclear puncta in germ cells of $r d e-3(+)$, but not $r d e-3(-)$, animals (Fig. 3d). pUG FISH coupled with immunofluorescence (IF) to detect a GFP- and degron-tagged RDE1253 showed that pUG RNA foci co-localized with RDE-3 and, therefore, Mutator foci (Fig. 3e). This data suggests that pUG RNAs are produced, function, and/or stored in Mutator foci in the $C$. elegans germline. Indeed, glp-1(q224) animals, which lack $\cong 99 \%$ of their germ cells when grown at $25^{\circ} \mathrm{C}$ (hereafter, glp-1(ts)), failed to produce detectable Tc1 pUG RNAs (or oma-1 dsRNAinduced oma-1 pUG RNAs) when grown at $25^{\circ} \mathrm{C}$, confirming that pUG RNAs are produced or stored in germ cells (Fig. 3f $)^{17}$. Incidentally, a related analysis with glp-1(ts) animals treated with dsRNA targeting the hypodermally-expressed $d p y-11$ gene ${ }^{13}$ showed that pUG RNAs can also be produced in somatic cells (Fig. 3f). Hereafter, however, we focus on exploring the biogenesis and function of pUG RNAs in the germline.

To explore further how germline pUG RNAs and Mutator foci might relate, we asked if the 135 glutamine/asparagine(Q/N) motif-rich protein MUT-16, which is required for Mutator foci assembly in germ cells ${ }^{16}$, was needed for pUG RNA biogenesis or function. mut-16(pk710) animals, which harbor a nonsense mutation in mut-16, produced oma-1 pUG RNAs in response to oma-1 dsRNA (Fig. 3g), but failed to silence oma-1 after an oma-1 pUG RNA injection (Fig. 3h). These data suggest that Mutator foci are required for pUG RNA-based gene silencing, downstream of pUG 140 RNA biogenesis.

pUG tails convert RNAs into templates for RNA-dependent RNA Polymerases

(RdRPs). RdRPs amplify RNAi-triggered gene silencing signals in C. elegans ${ }^{18}$. Current models 
posit that RdRPs: 1) are recruited to mRNAs by siRNAs generated from dsRNA, and 2) use these 45 mRNAs as templates to synthesize additional siRNAs, termed secondary $\left(2^{\circ}\right)$ siRNAs, which carry out gene silencing ${ }^{19-21}$. RRF-1, one of the four C. elegans RdRPs, localizes to Mutator foci ${ }^{16}$. We wondered whether pUG tails might promote gene silencing by recruiting RdRPs, such as RRF-1, to pUG RNAs, which could then act as templates for siRNA synthesis. To first ask if the pUG tail of a pUG RNA is sufficient to recruit RRF-1, we conjugated 5' biotinylated RNAs consisting of 5, 8,14 , or 18 UG repeats; 18 GC repeats; or 36 scrambled UGs to streptavidin beads and incubated these beads with extracts obtained from animals expressing HA::TagRFP::RRF-1. a-HA immunoblotting showed that HA::TagRFP::RRF-1 pelleted with $(U G)_{18}$, but not $(G C)_{18}$ or UG scrambled RNAs (Fig. 4a). Additionally, HA::TagRFP::RRF-1 pelleted strongly with (UG) ${ }_{14}$ and $(\mathrm{UG})_{18}$ RNAs, weakly with a (UG) $)_{8}$ RNA, and not with a (UG) $)_{5}$ RNA (Fig. 4b). These data show 155 that the RdRP RRF-1 interacts physically with UG repeat RNAs and that the sequence determinants of this interaction largely mirror those required for pUG tail-mediated gene silencing in vivo (Fig. 2c).

To determine whether pUG RNAs act as templates for RdRPs in vivo, we sequenced small (20-30nts) RNAs from animals injected with either an oma-1 pGC or pUG RNA engineered to contain a single-nucleotide polymorphism (SNP) not present in the genomic copy of oma-1. This SNP enabled differentiation of siRNAs templated from genomically-encoded oma-1 mRNAs versus those templated from injected oma-1(SNP) pGC or pUG RNAs. In C. elegans, RdRPderived $\left(2^{\circ}\right)$ siRNAs are also known as $22 \mathrm{G}$ siRNAs as they are typically antisense, $22 \mathrm{nt}$ in length and begin with a guanosine ${ }^{22}$. Small RNA sequencing showed that injection of the oma-1(SNP) 165 pUG RNA, but not the oma-1(SNP) pGC RNA, triggered the synthesis of oma-1 22G siRNAs mapping near (ミ100bp upstream) the site where the pUG tail was appended (Fig. 4c, Extended Data Fig. 5 and Table S3) ${ }^{23}$. For unknown reasons, both oma-1(SNP) pUG and pGC RNAs triggered non-pUG-specific siRNA synthesis $\cong 0.4 \mathrm{~kb}$ upstream of where the tails were appended. 
Importantly, most (92-100\%) pUG-specific 22G siRNAs encoded the complement of the engineered SNP, indicating that these siRNAs were templated from the injected oma-1(SNP) pUG RNA (Fig. 4c and Extended Data Fig. 5). We conclude that one function of a pUG tail is to convert RNAs into templates for RdRPs.

\section{pUG tails convert RNAs into vectors of transgenerational epigenetic inheritance}

175 (TEI). RNAi-triggered gene silencing can be inherited for multiple generations in C. elegans, making RNAi inheritance a robust and dramatic example of $\mathrm{TEI}^{24-29}$. Interestingly, a one-time exposure of animals to oma-1 dsRNA not only initiated the production of oma-1 pUG RNAs, but also caused oma-1 pUG RNAs to be expressed for four additional generations (Fig. 5a), concomitant with oma-1 gene silencing (Extended Data Fig. 6). Thus, pUG RNA expression correlates with gene silencing during TEI, consistent with the idea that pUG RNAs may contribute in some way to TEl. To test this idea, we injected animals with gfp or oma-1 pUG RNAs and monitored gfp or oma-1 silencing over generations. gfp or oma-1 pUG RNAs were sufficient to silence gfp or oma-1, respectively, for multiple generations (Fig. 5b and Extended Data Fig. 7). We conclude that pUG RNAs can induce TEI.

How might pUG RNAs drive TEI? We speculated that if pUG RNA-templated siRNAs (Fig. 4c and Extended Data Fig. 5) could direct de novo mRNA pUGylation, then generationally repeated cycles of pUG RNA-templated siRNA synthesis and siRNA-directed pUG RNA biogenesis could be maintained in the absence of initiating dsRNA triggers and, thus, drive TEI. Three lines of evidence support this "pUG/siRNA cycling" model for RNAi-directed TEI. First, $C$. elegans $2^{\circ}$ siRNAs can engage at least twelve AGO proteins (termed WAGOs) to mediate gene silencing ${ }^{30}$. MAGO12 animals, which lack all twelve of these WAGOs, produced oma-1 pUG RNAs after oma-1 RNAi (Fig. 5c). Progeny of RNAi-treated MAG012 animals, however, did not inherit the ability to produce oma-1 pUG RNAs (Fig. 5c). Thus, the $2^{\circ}$ siRNA system is needed to 
maintain pUG RNA expression specifically during the inheriting generations of TEI, which supports a pUG/siRNA cycling model for TEI. Interestingly, pUG RNAs derived from endogenous pUGylation targets $c 38 d 9.2$ and Tc1 were also dependent upon the WAGOs (Fig. 5d), suggesting that the endogenous targets of RDE-3 also undergo heritable silencing via pUG/siRNA cycling in the germline.

Second, when we injected animals with an oma-1(SNP) pUG RNA, pUG RNAs were 200 detectable in subsequent generations (Extended Data Fig. 8); however, these pUG RNAs did not contain the engineered SNP (Fig. 5e). Similarly, $<1 \%$ of siRNAs sequenced from progeny of oma1(SNP) pUG RNA injected animals possessed the SNP complement (Extended Data Fig. 8). Combined, these data show that most pUG RNAs and $2^{\circ}$ siRNAs expressed during the inheriting generations of RNAi-directed TEI result from de novo pUGylation events, supporting the idea that repeated pUG/siRNA cycling mediates TEI.

Third, we conducted a genetic analysis that showed that de novo pUGylation events in progeny were required for TEl. We crossed oma-1 RNAi-treated animals with rde-3(ne298) males, isolated $r d e-3(+)$ and $r d e-3(n e 298) F_{2}$ progeny, and then assayed the $F_{3}$ generation of this cross for oma-1 pUG RNA expression and oma-1 gene silencing (Fig. 5f). rde-3(ne298) animals failed

210 to express oma-1 pUG RNAs (Fig. 5f) or silence the oma-1 locus (Extended Data Fig. 8) during the inheriting generations of TEI, supporting the idea that pUG RNA biogenesis and, therefore, pUG/siRNA cycling in progeny is necessary for TEI maintenance. We conclude that pUG tails convert otherwise inert RNA fragments into drivers of a transgenerational RNA-based memory system, which is likely propagated across generations via iterative cycles of sense pUG RNA and 215 antisense siRNA biogenesis. 
Here, we show that RDE-3 adds 3' UG repeats to germline and soma-expressed RNAs in C. elegans, revealing a previously unknown form of RNA modification in vivo. RdRPs are recruited to pUG tails and use pUG RNAs, heretofore unrecognized RNA intermediates in the RNAi pathway, as templates for siRNA synthesis (Fig. $5 \mathrm{~g}$ ). Functional pUG tails consist of more than eight pairs of perfect or near-perfect 3' UG repeats. The precise sequence requirements for pUG tail function hint that pUG tails may form a structure which helps to recruit, and possibly prime, RdRPs. pUG tails/structures might also act as binding sites for other proteins, such as the $C$. elegans ortholog of the mammalian pUG binding protein TDP-43, to regulate the localization, stability, or function of pUG-tailed RNAs.

pUG RNAs act as informational vectors for TEI when they engage in feed-forward amplification cycles with RdRP-generated $2^{\circ}$ siRNAs (Fig. $5 \mathrm{~g}$ ). These pUG/siRNA cycles, we speculate, allow $C$. elegans to remember past gene silencing events and inoculate progeny against expressing unwanted and/or dangerous genetic elements. pUG/siRNA cycling likely occurs in Mutator foci, germline condensates whose assembly we find is required for pUG/siRNA pathway function (Fig. 5g). Experimental RNAi-initiated pUG/siRNA cycles perdure for several generations, but are not permanent, suggesting that $C$. elegans possess systems to prevent pUG/siRNA cycles from propagating in perpetuity. Interestingly, we find that RNAi-initiated pUG RNAs shorten progressively during TEI (Fig. 5a), suggesting that pUG RNA shortening, which may be an inevitable consequence of RdRP-based $2^{\circ}$ siRNA synthesis (Extended Data Fig. 9), could function as one such brake on TEI. In contrast, the natural targets of pUGylation, such as transposons, are constitutively silenced by the pUG/siRNA system, suggesting that genetic systems, such as genomically-encoded PIWI-interacting (pi)RNAs or endogenous dsRNAs, are likely to reinforce and refocus epigenetic pUG/siRNA silencing at these loci each generation (Fig. 5g). 
The logic of the C. elegans sense-antisense pUG/siRNA TEI system resembles that of fly and mammalian piRNA "ping-pong" systems in which iterative base-pairing between genomicallyencoded sense-antisense transposon RNAs, as well as piRNAs derived from these RNAs, mediates stable transposon silencing ${ }^{31}$. We speculate that related sense-antisense RNA systems could contribute to other biological processes during which long-term memories of past expression states are needed, such as development or inheritance of environmentally-triggered acquired traits $^{32-37}$. Finally, our data show that long non-templated and non-homopolymeric tracts of ribonucleotides can be appended to, and confer novel functions to, RNAs in C. elegans. It will be of obvious interest to ask whether pUG-tailed RNAs, or RNAs bearing other unexpected tails, are restricted to $C$. elegans or are, instead, emissaries of a new class of eukaryotic RNAs. 


\section{Figure Legends}

Figure 1. pUG tails are added to mRNA fragments in vivo. a, PCR-based assay to detect gene-specific pUG RNAs. Total RNA was reverse transcribed (RT) using an (AC) $)_{9}$ oligo modified with two PCR adapters and then degraded using RNase $\mathrm{H}$. Two rounds of PCR were performed using gene-specific and adapter-specific primers. Note: the $(A C)_{9}$ RT oligo can complementary base-pair anywhere along the length of a pUG tail. b, oma-1 pUG PCR was performed on total RNA isolated from wild-type animals and two different rde-3 mutant strains fed E. coli expressing empty vector control or oma-1 dsRNA (RNAi). RDE-3 function was rescued in ne3370 and ne298 animals (see Main text and Methods for details). gsa-1, which has an 18nt long genomically-encoded pUG repeat in its 3'UTR, is a loading control. c, oma-1 pUG PCR on RNA isolated from animals of the indicated genotypes, +/- oma-1 dsRNA. d, Sanger sequencing chromatogram of an oma-1 pUG PCR product showing that a pUG tail consists of perfect UG repeats and is longer than the RT oligo. e, Illumina MiSeq was performed on oma-1 pUG PCR products derived from wild-type and rde-3(-) animals +/- oma-1 dsRNA. \# of sequenced pUG RNAs (y-axis) mapping to each pUGylation site (x-axis) is shown. Inset: total number of sequenced and spliced oma-1 pUG RNAs from indicated samples. $\mathbf{f}$, \% of oma-1 pUG RNAs (MiSeq reads) having each nucleotide (nt) at the last templated position ( -1 ) is indicated. Logo analysis was used to determine the probability of finding each $\mathrm{nt}$ at both the first position of a pUG tail (+1), as well as at the second-to-last templated nt of oma-1 (-2).

Figure 2. pUG tails convert otherwise inert RNAs into agents of gene silencing. a, Fluorescent micrographs showing -1 to -3 oocytes of adult rde-1(ne219); gfp::h2b animals injected in the germline with RNAs consisting of the indicated 3' terminal repeats appended to the first 369nt of gfp mRNA. \% of progeny with gfp silenced was counted. b, oma-1(zu405ts) animals lay arrested embryos at $20^{\circ} \mathrm{C}$ unless oma-1(zu405ts) is silenced ${ }^{14}$. Adult rde-1(ne219); oma-1(zu405ts) animals were injected with RNAs consisting of the indicated 3' terminal repeats appended to the first 541nt of oma-1 mRNA. c, Adult rde-1(ne219); oma-1(zu405ts) animals were injected with the same oma-1 mRNA fragment as in b with varying 3' pUG tail length, different UG repeat sequences or with the pUG sequence appended to the 3' end, 5' end or in the middle of the oma-1 mRNA. b-c, 5 progeny per injected animal were pooled and the \% hatched embryos (\# of hatched embryos/total embryos laid) was counted. Insets show injected RNAs run on a $2 \%$ agarose gel to assess RNA integrity. $n=5-15$ injected animals. a-c, Repeats 
were 36nt in length unless otherwise indicated. Error bars are standard deviations (s.d.) of the mean.

Figure 3. Endogenous RNAs are pUGylated and localize to germline Mutator foci. a, Total RNA isolated from adult wild-type or rde-3 mutant animals was subjected to Tc1 pUG PCR analysis (Fig. 1a). Rescue strategies are described in the Main text and Methods. b, A 36nt pUG tail was appended to a 338nt Tc1 RNA fragment and this Tc1 pUG RNA was injected into germlines of rde-3(-); unc-22::tc1 animals with a co-injection marker. 25 co-injection marker expressing progeny were pooled per injected animal. Each data point represents the \# of mobile progeny (indicating Tc1 mobilized from unc-22) per pool. Error bars represent s.d. c-e, Fluorescent micrographs of adult pachytene germ cell nuclei. c, Wild-type or rde-3(-) animals expressing a marker of chromatin (mCherry:HIS-58, magenta) and C38D9.2::GFP (green), which is expressed diffusely in the germline syncytium, wherein germ cell nuclei share a common cytoplasm. d, RNA FISH to detect pUG RNAs (pUG RNA FISH) was performed on germlines dissected from wild-type or rde-3(-) animals using an 18nt long poly(AC) oligo conjugated to Alexa 647 (magenta). RNA FISH to detect ama-1 mRNA (green) was performed simultaneously as a positive control. DNA was stained with DAPI (blue). e, pUG RNA FISH (magenta) and immunofluorescence to detect a GFP- and degron-tagged RDE-3 (green). DNA was stained with DAPI (blue). f, Tc1, $d p y-11$, and oma-1 pUG PCR was performed on total RNA isolated from $\mathrm{glp}-1$ (q224 or ts) animals grown at $15^{\circ} \mathrm{C}$ (permissive temperature, germ cells present) or $25^{\circ} \mathrm{C}$ (non-permissive temperature, $<99 \%$ of germ cells) fed empty vector control or oma-1 and dpy-11 dsRNA simultaneously. g, oma-1 pUG PCR was performed on total RNA extracted from wild-type, rde-3(-), and mut-16(pk710) animals +/- oma-1 dsRNA. Note: pUG RNAs appear longer in mut-16 mutants (see Extended Data Fig. 9 legend). h, Control, rde-8(tm2252) or mut-16(pk710) animals (all rde-1(ne219); oma-1(zu405ts) background) were injected with oma-1 pUG RNAs and \% embryos hatched was scored. Error bars +/- s.d. n=8-12 injected animals.

Figure 4. pUG RNAs are templates for RdRPs. a-b, The indicated 5' biotinylated RNA oligos were conjugated to streptavidin beads. Beads were then incubated with extracts generated from animals expressing an HA- and tagRFP-tagged RRF-1 and pelleted to separate beads (pull-down) from supernatant (sup). Both pull-down and sup fractions were subjected to a-HA immunoblotting. c, rde-1(ne219); oma-1(zu405ts) animals were injected with a SNP-containing 
(dotted line) oma-1 (oma-1(SNP)) pUG or pGC RNA. Injected animals were collected 1-4 hours after injection and small RNAs (20-30nts) were sequenced. In C. elegans, RdRP-derived small RNAs are antisense, 22nt in length, and initiate with guanosine (termed secondary siRNAs or $22 \mathrm{G}$ siRNAs) ${ }^{22}$. 22G siRNAs mapping antisense to oma-1 are shown. Injection of an oma-1(SNP) pUG (but not pGC) RNA triggered 22G siRNA production near the site of the pUG tail (pUG-specific). 100\% of these pUG-specific 22G siRNAs contained the engineered SNP. Both oma-1(SNP) pUG and pGC RNA injections triggered small RNA production 5' of the pUG tail (non-specific). The origin of non-specific siRNAs is not known. For a list of all small RNAs sequenced, see Table S3.

Figure 5. pUG RNAs and siRNAs cooperate to drive heritable gene silencing. a, oma-1 pUG PCR was performed on RNA isolated from four generations of descendants $\left(F_{1}-F_{4}\right)$ derived from oma-1 dsRNA-treated animals. b, rde-1(ne219); gfp::h2b animals were injected with a gfp pUG RNA and gfp expression was monitored for six generations. c, MAGO12 animals, which harbor deletions in all twelve wago genes, were treated with oma-1 dsRNA. oma-1 pUG PCR was performed on total RNA from dsRNA-treated animals $\left(P_{0}\right)$ and their progeny $\left(F_{1}\right)$. Note: pUG RNAs appear longer in MAGO12 animals (see Extended Data Fig. 9 legend). d, c38d9.2 and Tc1 pUG RNA expression levels were quantified in embryos harvested from wild-type, MAG012, or rde-3(-) animals. Shown is the fold change normalized to rde-3(-). e, rde-1(ne219); oma-1(zu405ts) animals were injected with an oma-1(SNP) pUG RNA. pUG RNAs were Sanger sequenced from $\mathrm{F}_{2}$ progeny to determine the presence or absence of the SNP. $\mathbf{f}$, Wild-type and rde-3(ne298) animals subjected to oma-1 RNAi were crossed and $F_{2}$ progeny were genotyped (not shown). RNA isolated from populations of $r d e-3(+)$ or $r d e-3(n e 298) \mathrm{F}_{3}$ animals (3 biological replicates) was subjected to oma-1 pUG PCR. g, Model. Two major phases of the pUG RNA pathway, initiation and maintenance, are shown. Initiation: exogenous and constitutive (i.e. genomically-encoded such as dsRNA, piRNAs) triggers direct RDE-3 to pUGylate RNAs previously fragmented by RNAi, and possibly other, systems. Maintenance: pUG RNA are templates for RdRPs to make $2^{\circ}$ siRNAs. Argonaute proteins (termed WAGOs) bind these $2^{\circ}$ siRNAs and: 1) target homologous RNAs for transcriptional and translational silencing (previous work $^{25,30,38,39}$ ), and 2) direct the cleavage and de novo RDE-3-mediated pUGylation of additional mRNAs (this work). In this way, cycles of pUG RNA-based siRNA production and siRNA-directed mRNA pUGylation form a silencing loop, which is maintained over time and across generations to mediate stable gene silencing. pUG/siRNA cycling likely occurs in 
bioRxiv preprint doi: https://doi.org/10.1101/2019.12.31.891960; this version posted December 31, 2019. The copyright holder for this preprint (which was not certified by peer review) is the author/funder, who has granted bioRxiv a license to display the preprint in perpetuity. It is made available under aCC-BY-NC-ND 4.0 International license.

germline perinuclear condensates called Mutator foci. 


\section{Extended Data Figure Legends}

Extended Data Fig. 1. RNAi-triggered pUGylation is general and sequence-specific. a, $g f p:: h 2 b$, rde-3(-); gfp::h2b and WT (no gfp::h2b) animals were fed E.coli expressing either empty vector control or gfp dsRNA. b, WT and rde-3(-) animals were fed E.coli expressing empty vector control and either oma-1 or dpy-11 dsRNA. gfp (a), dpy-11 and oma-1 (b) pUG RNAs were detected using the assay outlined in Fig. 1a.

Extended Data Fig. 2. pUG RNA-directed gene silencing is specific. a, rde-1(ne219); oma-1(zu405ts) animals were injected with either an oma-1 or gfp pUG RNA. Inset shows injected RNAs run on a $2 \%$ agarose gel to assess RNA integrity. b, rde-1(ne219); gfp::h2b animals were injected with either an oma-1 or gfp pUG RNA. \% embryonic arrest (a) and \% gfp silencing (b) were scored. All pUG tails were $36 \mathrm{nt}$ in length. $n=6-10$ injected animals.

Extended Data Fig. 3. pUG tails must be appended to sense RNAs of $>50$ nts for functionality. rde-1(ne219); oma-1(zu405ts) animals were injected with: a, an oma-1 pUG RNA consisting of the sense or antisense strand of the same 541nt long oma-1 mRNA fragment (beginning at the atg) and a 36nt 3' pUG tail. b, oma-1 pUG RNAs consisting of oma-1 mRNA fragments of varying lengths (with position 1 starting at the aug of the oma-1 mRNA sequence) all appended to a 36nt pUG tail. For $\mathbf{a}$ and b, \% embryonic arrest was scored at the non-permissive temperature for oma-1(zu405ts). n=8-17 injected animals.

Extended Data Fig. 4. Endogenous targets of pUGylation in C. elegans. Total RNA was extracted from WT or rde-3(-) animals. The assay outlined in Fig. 1a was used to detect pUG RNAs for a-b, RNAs that were significantly upregulated in rde-3(-) animals; and c, two randomly selected RNAs whose expression does not change in rde-3(-) mutants. Data is representative of 3 biological replicates. The same RT samples were used for panels $\mathbf{b}$ and $\mathbf{c}$ and, therefore, the gsa-1 loading control is the same for both panels.

Extended Data Fig. 5. pUG RNAs are templates for RdRPs. A biological replicate of the experiment shown in Fig. 4c was performed. oma-1(SNP) pUG or pGC RNAs were injected into rde-1(ne219); oma-1(zu405ts) germlines. SNP is indicated with the dotted line. Total RNA was isolated 4-6 hours after injection and small RNAs (20-30nts) were sequenced. 22G siRNAs 
mapping antisense to oma-1 are shown. oma-1 pUG (but not pGC) RNA triggered 22G siRNA production near the site of the pUG tail (pUG-specific 22G siRNAs). For unknown reasons, both pUG and pGC RNA injections triggered small RNA production $\cong 400 \mathrm{bp} 5$ ' of either tail.

Extended Data Fig. 6. oma-1 dsRNA triggers heritable silencing. oma-1(zu405ts) animals were fed oma-1 dsRNA and \% embryos hatched was scored for 5 generations. Data represents one biological replicate.

Extended Data Fig. 7. pUG RNA injection triggers heritable silencing. rde-1(ne219); oma-1(zu405ts) animals were injected with co-injection marker +/- oma-1 pUG RNA and \% embryonic arrest was scored for four generations in lineages of animals established from injected parents. The data show that oma-1(zu405ts) is silenced for multiple generations after an oma-1 pUG RNA injection.

Extended Data Fig. 8. de novo pUGylation events in progeny are required for TEI. a, rde-1(ne219); oma-1(zu405ts) animals were injected with an oma-1(SNP) pUG RNA or with co-injection marker only. Co-injection marker-expressing $F_{1}$ progeny were picked and allowed to lay their $F_{2}$ broods. oma-1 pUG PCR was performed on total RNA from $F_{2}$ progeny. $b$, Two biological replicates of $22 \mathrm{G}$ siRNAs sequenced from the progeny of rde-1(ne219); oma-1(zu405ts) animals injected with oma-1(SNP) pUG or pGC RNAs are shown. Dotted line indicates location of SNP. 22G siRNA reads were normalized to total number of reads. In Fig. 4c and Extended Data Fig. 5, 22G siRNAs were sequenced 4-6 hours after injection and 100\% were found to encode the complement of the engineered oma-1 SNP. Shown here, $<1 \%$ of $22 \mathrm{G}$ siRNAs from progeny of injected animals encoded the SNP complement (insets). Note: siRNAs mapping near the pUG tail were observed only after oma-1(SNP) pUG RNA injection (pUG-specific siRNAs). For unknown reasons, both oma-1(SNP) pUG and pGC RNAs triggered small RNA production 5' of the pUG-specific siRNAs. It is possible that these siRNAs were triggered by the piRNA system. Further work will be needed to ascertain the etiology of these RNAs. c, oma-1(zu405ts) and rde-3(ne298); oma-1(zu405ts) animals were fed and mated on oma-1 dsRNA. $F_{2}$ progeny from this cross were genotyped for rde-3(ne298) and $F_{3}$ progeny were phenotyped for \% embryonic arrest. 3 biological replicates $\left(P_{0} 1-3\right)$ were performed at the non-permissive temperature for oma-1(zu405ts). Error bars are +/- s.d. 
Extended Data Fig. 9. pUG RNA shortening may act as a brake on TEl. a, The gel shown is the same as in Fig. 5a, except that oma-1 pUG RNAs from the $\mathrm{P}_{0}$ generation are included. $\mathbf{b}$, oma-1 pUG RNA reads from MiSeq were mapped to oma-1 and the length of the oma-1 mRNA portion of each pUG RNA was determined (y-axis). Shown is a Box and Whisker plot representing the interquartile range (IQR, box) and median (line in the box) of lengths at the indicated generations after dsRNA-treatment. The y-axis starts at the aug of the oma-1 mRNA. The whiskers extend to values below and above $1.5^{*} \mathrm{IQR}$ from the first and third quartiles, respectively. Data beyond the end of the whiskers are outliers and plotted as points. The data support the gel in a, showing that pUG RNAs get shorter in each generation during RNAi-directed TEI. c, A "ratchet" model to explain pUG RNA shortening. pUG RNA shortening may be due to the $3^{\prime} \rightarrow 5^{\prime}$ directionality of RdRPs, which causes each turn of the pUG/siRNA cycle (see model in Fig. $5 \mathrm{~g}$ ) to trigger cleavage and pUGylation of target mRNAs at sites more 5' than in the previous cycle until, eventually, pUG RNAs are too short to act as RdRP templates, thereby ending the cycle. Additional support for the ratchet model comes from Fig. $3 \mathrm{~g}$ and $5 \mathrm{c}$, which show that RNAi-triggered pUG RNAs are longer in mut-16 and MAGO12 mutant animals than in wild-type animals. Our data indicates that loss of MUT-16 or the WAGOs blocks pUG/siRNA cycling, suggesting that MUT-16 and the WAGOs act during the pUG/siRNA cycling phase of pUG RNA-mediated gene silencing (see model in Fig. $5 \mathrm{~g}$ ). In the absence of cycling, pUG shortening does not occur and pUG RNAs are longer in mut-16 and MAGO12 animals. Finally, a number of recent studies report transgenerational inheritance of acquired traits in C. elegans, which last 3-4 generations ${ }^{32-37}$. oma-1 RNAi-directed pUG RNAs also perdure for 3-4 generations (Fig. 5a). These shared generational timescales of inheritance suggest that the inheritance of acquired traits in $C$. elegans may be mediated by pUG RNAs whose generational "half-life" is limited to 3-4 generations due to the built-in brake on TEI provided by pUG RNA shortening. 


\section{Supplementary Tables}

Table S1. pUG RNA sequencing data. This table contains oma-1 pUG RNA reads from miSeq, our calculations of the accuracy of pUG tails and Tc1 pUG RNAs sequenced using Sanger sequencing.

Table S2. Genes upregulated in rde-3 mutants. List of upregulated RNAs in rde-3(-) mutants (adjusted $p$ value $<0.05$ and log2fold change $>1.5$ ).

Table S3. Small RNA reads mapping to oma-1. oma-1 small RNAs sequenced after oma-1(SNP) pUG and pGC RNA injections (with a no injection control) in either the injected generation or from the progeny of injected animals.

Table S4. Oligos, C. elegans strains and pUG RNAs used in this study. 


\section{References for main text and figure legends}

1. Fire, A. et al. Potent and specific genetic interference by double-stranded RNA in Caenorhabditis elegans. Nature 391, 806-811 (1998).

2. Collins, J., Saari, B. \& Anderson, P. Activation of a transposable element in the germ line but not the soma of Caenorhabditis elegans. Nature 328, 726-728 (1987).

3. Ketting, R. F., Haverkamp, T. H. A., van Luenen, H. G. A. M. \& Plasterk, R. H. A. mut-7 of C. elegans, Required for Transposon Silencing and RNA Interference, Is a Homolog of Werner Syndrome Helicase and RNaseD. Cell 99, 133-141 (1999).

4. Tabara, H. et al. The rde-1 gene, RNA interference, and transposon silencing in C. elegans. Cell 99, 123-132 (1999).

5. Chen, C.-C. G. et al. A member of the polymerase beta nucleotidyltransferase superfamily is required for RNA interference in C. elegans. Curr. Biol. 15, 378-383 (2005).

6. Aravind, L. \& Koonin, E. V. DNA polymerase beta-like nucleotidyltransferase superfamily: identification of three new families, classification and evolutionary history. Nucleic Acids Res. 27, 1609-1618 (1999).

7. Martin, G. \& Keller, W. RNA-specific ribonucleotidyl transferases. RNA 13, 1834-1849 (2007).

8. Preston, M. A. et al. Unbiased screen of RNA tailing activities reveals a poly(UG) polymerase. Nat. Methods 16, 437-445 (2019).

9. Detwiler, M. R., Reuben, M., Li, X., Rogers, E. \& Lin, R. Two zinc finger proteins, OMA-1 and OMA-2, are redundantly required for oocyte maturation in C. elegans. Dev. Cell 1, 187-199 (2001).

10. Parrish, S. \& Fire, A. Distinct roles for RDE-1 and RDE-4 during RNA interference in 
Caenorhabditis elegans. RNA 7, 1397-1402 (2001).

11. Tabara, H., Yigit, E., Siomi, H. \& Mello, C. C. The dsRNA binding protein RDE-4 interacts with RDE-1, DCR-1, and a DExH-box helicase to direct RNAi in C. elegans. Cell 109, 861-871 (2002).

12. Tsai, H.-Y. et al. A ribonuclease coordinates siRNA amplification and mRNA cleavage during RNAi. Cell 160, 407-419 (2015).

13. Ko, F. C. F. \& Chow, K. L. A novel thioredoxin-like protein encoded by the C. elegans dpy-11 gene is required for body and sensory organ morphogenesis. Development 129 , 1185-1194 (2002).

14. Lin, R. A gain-of-function mutation in oma-1, a C. elegans gene required for oocyte maturation, results in delayed degradation of maternal proteins and embryonic lethality. Dev. Biol. 258, 226-239 (2003).

15. Voronina, E., Seydoux, G., Sassone-Corsi, P. \& Nagamori, I. RNA granules in germ cells. Cold Spring Harb. Perspect. Biol. 3, (2011).

16. Phillips, C. M., Montgomery, T. A., Breen, P. C. \& Ruvkun, G. MUT-16 promotes formation of perinuclear mutator foci required for RNA silencing in the C. elegans germline. Genes Dev. 26, 1433-1444 (2012).

17. Austin, J. \& Kimble, J. glp-1 is required in the germ line for regulation of the decision between mitosis and meiosis in C. elegans. Cell 51, 589-599 (1987).

18. Sijen, T. et al. On the role of RNA amplification in dsRNA-triggered gene silencing. Cell 107, 465-476 (2001).

19. Ambros, V., Lee, R. C., Lavanway, A., Williams, P. T. \& Jewell, D. MicroRNAs and other tiny endogenous RNAs in C. elegans. Curr. Biol. 13, 807-818 (2003).

20. Sijen, T., Steiner, F. A., Thijssen, K. L. \& Plasterk, R. H. A. Secondary siRNAs result from 
unprimed RNA synthesis and form a distinct class. Science 315, 244-247 (2007).

21. Pak, J. \& Fire, A. Distinct Populations of Primary and Secondary Effectors During RNAi in C. elegans. Science 315, 241-244 (2007).

22. Gu, W. et al. Distinct argonaute-mediated 22G-RNA pathways direct genome surveillance in the C. elegans germline. Mol. Cell 36, 231-244 (2009).

23. Billi, A. C., Fischer, S. E. J. \& Kim, J. K. Endogenous RNAi pathways in C. elegans. WormBook 1-49 (2014).

24. Vastenhouw, N. L. et al. Gene expression: long-term gene silencing by RNAi. Nature 442 , 882 (2006).

25. Buckley, B. A. et al. A nuclear Argonaute promotes multigenerational epigenetic inheritance and germline immortality. Nature 489, 447-451 (2012).

26. Ashe, A. et al. piRNAs can trigger a multigenerational epigenetic memory in the germline of C. elegans. Cell 150, 88-99 (2012).

27. Shirayama, M. et al. piRNAs Initiate an Epigenetic Memory of Nonself RNA in the C. elegans Germline. Cell 150, 65-77 (2012).

28. Luteijn, M. J. et al. Extremely stable Piwi-induced gene silencing in Caenorhabditis elegans. EMBO J. 31, 3422-3430 (2012).

29. Sapetschnig, A., Sarkies, P., Lehrbach, N. J. \& Miska, E. A. Tertiary siRNAs mediate paramutation in C. elegans. PLoS Genet. 11, e1005078 (2015).

30. Yigit, E. et al. Analysis of the C. elegans Argonaute family reveals that distinct Argonautes act sequentially during RNAi. Cell 127, 747-757 (2006).

31. Czech, B. et al. piRNA-Guided Genome Defense: From Biogenesis to Silencing. Annu. Rev. Genet. 52, 131-157 (2018).

32. Remy, J.-J. Stable inheritance of an acquired behavior in Caenorhabditis elegans. Curr. 
Biol. 20, R877-8 (2010).

33. Rechavi, O. et al. Starvation-induced transgenerational inheritance of small RNAs in C. elegans. Cell 158, 277-287 (2014).

34. Schott, D., Yanai, I. \& Hunter, C. P. Natural RNA interference directs a heritable response to the environment. Sci. Rep. 4, 7387 (2014).

35. Jobson, M. A. et al. Transgenerational Effects of Early Life Starvation on Growth, Reproduction, and Stress Resistance in Caenorhabditis elegans. Genetics 201, 201-212 (2015).

36. Moore, R. S., Kaletsky, R. \& Murphy, C. T. Piwi/PRG-1 Argonaute and TGF- $\beta$ Mediate Transgenerational Learned Pathogenic Avoidance. Cell 177, 1827-1841.e12 (2019).

37. Posner, R. et al. Neuronal Small RNAs Control Behavior Transgenerationally. Cell 177, 1814-1826.e15 (2019).

38. Guang, S. et al. An Argonaute transports siRNAs from the cytoplasm to the nucleus. Science 321, 537-541 (2008).

39. Guang, S. et al. Small regulatory RNAs inhibit RNA polymerase II during the elongation phase of transcription. Nature vol. 465 1097-1101 (2010). 


\section{Methods}

Genetics. C. elegans culture and genetics were performed as described previously ${ }^{1}$. Unless otherwise noted, all C. elegans strains (see Table S4) were maintained at $20^{\circ} \mathrm{C}$ on NGM growth media and fed OP50 bacteria.

RNAi. Embryos were obtained via hypochlorite treatment of gravid adult hermaphrodites (egg prep) and dropped onto plates seeded with HT115 bacteria expressing dsRNA against a gene of interest. After 3-4 days, gravid adults were washed off plates using M9 + Triton X-100 buffer, collected in Trizol, flash frozen in liquid nitrogen and stored at $-80^{\circ} \mathrm{C}$ until total RNA extraction.

10 The dpy-11 and one of the oma-1 RNAi clones came from the C. elegans RNAi collection (Ahringer lab). The second oma-1 RNAi clone was a custom clone made to target exon 6 of oma1. The gfp RNAi clone was obtained from the Fire lab. For transgenerational RNAi inheritance experiments, embryos were seeded onto plates with either empty vector control or dsRNA of interest. Some gravid adults were collected for the $\mathrm{P}_{0}$ generation sample and the remaining were egg prepped onto plates without dsRNA every generation, for the indicated number of generations.

pUG PCRs and qPCRs. Total RNA was extracted using TRIzol Reagent (Life Technologies, 15596018). 5ug of total RNA and $1 \mathrm{pmol}$ of reverse transcription oligo was used to generate firststrand cDNA using the Superscript III First-Strand Synthesis System (Invitrogen, 18080051). 1ul of cDNA was used for the first PCR (20ul volume) performed with Taq DNA polymerase (New England BioLabs, M0273) and primers listed in Table S4. First PCR reactions were diluted 1:100 and then $1 \mathrm{ul}$ was used for a second PCR (50ul volume) using primers listed in Table S4. PCR reactions were then run on agarose gels. For Sanger sequencing, lanes of interest were cut out

25 from agarose gels and gel extracted using a QIAquick Gel Extraction Kit (Qiagen, 28706). 3ul of gel extracted PCR product was used for TA cloning with the pGEM®-T Easy Vector System 
(Promega, A1360) according to manufacturer's instructions. Ligation reactions were incubated overnight at $4^{\circ} \mathrm{C}$. Transformations were performed with 5-alpha Competent E. coli cells (NEB, $\mathrm{C} 2987 \mathrm{H}$ ) and plated on LB/ampicillin/IPTG/X-Gal plates. White colonies were selected, inoculated and miniprepped using QIAprep Spin Miniprep Kit (Qiagen, 27106). Plasmids were sequenced at the Dana-Farber/Harvard Cancer Center DNA Resource Core using a universal SP6 primer (5'-CATACGATTTAGGTGACACTATAG-3'). qPCRs were performed using 2ul of 1:100 diluted first PCRs as a template with qPCR primers (Table S4) and iTaq Universal SYBR Green Supermix (Bio-Rad) according to manufacturer's instructions.

MiSeq. oma-1 pUG PCRs were sequenced on an Illumina MiSeq from animals fed HT115 bacteria expressing empty vector control plasmid, oma-1 dsRNA from the Ahringer RNAi library or our custom oma-1 dsRNA ( $\mathrm{P}_{0}-\mathrm{F}_{4}$ generations for this experiment). A first round of PCR was performed with the same primers as described above. Primers were modified for the second PCR to contain Illumina $p 5$ and $p 7$ sequences, read 1 and 2 sequencing primers, a unique index (reverse primer only) for multiplexing and unique molecular identifiers (NNN) (Table S4). PCR reactions were then pooled, run on an agarose gel and gel purified as described above. Sequencing was performed on an Illumina MiSeq to obtain paired-end reads (67bp for Read 1, 248bp for Read 2).

MiSeq sequencing analysis. First, unique molecular identifiers (UMIs) were removed from each read pair and appended to the end of the read name using UMI-tools ${ }^{2}$. Then, cutadapt v2.5 was used for the following: 1) low-quality bases (quality score < 20) were trimmed from the 3' ends of reads; 2) read pairs containing the inline portion of the 5' adapter 50 (AACAACGAGAAGATCGATGA) in Read 1 were selected for and then trimmed; 3) Read pairs containing the inline portion of the $3^{\prime}$ adapter (GGCGTCGCCATATTCTACTTACACACACACACACACAC) in Read 2 were selected for and 
trimmed; and 4) If the 5' adapter was present in any Read 2 sequences, the adapter was trimmed from those sequences ${ }^{3}$. After adapter trimming, Read 2 sequences were screened for additional pACs at the 5' end: reads that did not contain additional pACs (and therefore did not have a pUG tail longer than the adapter) were discarded; reads that did contain additional pACs were retained, and the pACs were trimmed using cutadapt $\mathrm{v} 2.5$ ( $\mathrm{pAC}$ and $\mathrm{pCA}$ sequences were provided as non-internal 5' adapters) ${ }^{3}$. After pAC trimming, Read 2 sequences shorter than 5 nucleotides were discarded. The remaining Read 2 sequences were aligned to the C. elegans genome (WormBase release WS260) using STAR v2.7.0f ${ }^{4}$. SAM and BED files of unique alignments were generated using SAMtools v1.9 and BEDtools v2.27.1 and then imported into R for subsequent analyses ${ }^{5-7}$. Alignments were deduplicated based on the combination of the UMI and end coordinate. Alignments that mapped to the "+" strand and/or to coordinates outside of the oma-1 gene were discarded.

To systematically define the "oma-1" and "pUG" portions of each read, the pre-pACtrimmed version of the read was reverse-complemented and then split as follows. By default, the aligned portion of the read was designated as "oma-1", and any sequence downstream of the aligned portion was designated as the "pUG." Then, the "oma-1" portion was matched to an oma1 reference sequence (spliced + UTRs) using Biostrings v2.50. $2^{8}$. If the first 1-6 nucleotides that occurred 3' of the match were the same in the oma-1 reference as they were in the read prior to pAC trimming (and therefore had the potential to be templated), then those nucleotides were reassigned to the "oma-1" portion of the read. End coordinates of the alignments were adjusted accordingly. A small portion of reads $(<15 \%)$ were misannotated with the above approach, largely due to soft-clipping at the 3' end during alignment. To systematically filter out such reads, reads

75 for which the annotated "pUG" started with a base other than " $U$ " or "G" and/or contained 2 or more bases other than "U" or "G" within the "pUG" sequence were discarded. The abundance of each pUGylation site (Figure 1e) was plotted in R using Sushi v1.20.0 ${ }^{9}$. To generate the pUG site 
logos shown in Figure 1f, a list of unique pUG sites was sorted by the last nucleotide of the "oma1 " portion and then plotted in R using ggseqlogo $\mathrm{v} 0.1^{10}$.

80

pUG RNA injections. gfp and oma-1 pUG RNAs. pUG RNAs were synthesized in vitro using MEGAscript T7 Transcription Kit (Invitrogen, AM1334). DNA templates for in vitro transcription reactions were gel purified PCR products amplified using primers listed in Table S4. 150ng of gel purified PCR products was used as a template. Reactions were incubated overnight at $37^{\circ} \mathrm{C}$. in

85 vitro transcribed RNA was purified using TRIzol Reagent (Life Technologies, 15596018) and stored at $-80^{\circ} \mathrm{C}$. Injection mix consisted of $0.5 \mathrm{pmol} / \mathrm{ul}$ in vitro transcribed RNA and $2.5 \mathrm{ng} / \mathrm{ul}$ coinjection marker (pmyo-2::mCherry::unc-54 3'UTR) plasmid pCFJ90 (Addgene, plasmid \#19327), dissolved in water. Animals expressing co-injection marker show mcherry expression in the pharynx. Adult hermaphrodites ((either gfp::h2b; rde-1(ne219) for gfp pUG RNA injections or oma-

90 1(zu405); rde-1(ne219) for oma-1 pUG RNA injections) were injected in the germline and allowed to recover at $15^{\circ} \mathrm{C}$ for two days before being shifted back to $20^{\circ} \mathrm{C}$. Adult progeny of injected animals expressing mcherry in the pharynx were picked under an Axis Zoom.V16 fluorescent dissecting microscope using a PlanNeoFluar Z 1x/0.25 FWD 56mm objective and scored gfp or oma-1 expression. gfp expression was scored using the Plan-Apochromat $20 \times / 0.8$ M27 objective on an Axio Observer.Z1 fluorescent microscope (Zeiss). Images were taken with the PlanApochromat $63 \times$ /1.4 Oil DIC M27 objective. oma-1(zu405ts) is a gain-of-function temperaturesensitive allele of oma-1. oma-1(zu405ts) animals lay arrested embryos at $20^{\circ} \mathrm{C}^{11}$, unless oma1 (zu405ts) is silenced. To measure oma-1(zu405ts) silencing, five progeny from each injected animal were transferred to a new plate. Animals were removed after laying 50-100 eggs, and oma-1(zu405) silencing was measured as percentage of eggs hatched. Tc1 pUG RNA. T7 in vitro transcription was performed as described above to synthesize a Tc1 pUG RNA consisting of a 36nt pUG tail appended to a 338nt long fragment of Tc1 RNA (see Table S4 for primers used). This Tc1 pUG RNA was injected (as above) into the germlines of rde-3(ne3370); unc-22(st136) 
animals. unc-22(st136) animals have a Tc1 DNA transposon insertion in the unc-22 gene, resulting is paralysis. Co-injection marker-expressing progeny of injected animals were picked at the L4 stage and pooled (25 animals per pool) onto 10cM NGM plates and allowed to lay a brood. The number of mobile adult progeny in each pool was counted 6-7 days later.

RNA FISH + Immunofluorescence. Approximately 30 animals were dissected in $15 \mu$ of $1 \mathrm{X}$ egg 110 buffer (25 mM HEPES ( $\mathrm{pH} 7.3), 118 \mathrm{mM} \mathrm{NaCl}_{2}, 48 \mathrm{mM} \mathrm{KCl}, 2 \mathrm{mM} \mathrm{CaCl} 2,2 \mathrm{mM} \mathrm{MgCl}_{2}$ ) to isolate gonads. A coverslip was placed on top of dissected tissue, excess buffer was soaked up using a Kimwipe and slides were placed onto a metal block pre-chilled on dry ice for $10 \mathrm{~min}$. Coverslips were popped off and slides were submerged in methanol at $-20^{\circ} \mathrm{C}$ for $10 \mathrm{~min}$. Slides were then washed twice, 5 min per wash in 1X PBS $+0.1 \%$ Tween-20 (PBSTW). Samples were then fixed with $4 \%$ paraformaldehyde solution in $1 \mathrm{X}$ PBS for 20 minutes, followed by two 5 min washes in PBSTW. Samples were then incubated at $37^{\circ} \mathrm{C}$ for 6 hours in a humid chamber with a 1:50 dilution of fluorescent RNA FISH probe in hybridization buffer (10\% formamide, 2 X SSC, $10 \%$ dextran sulfate $(w / v))$. The RNA FISH probe to detect pUG RNAs (/5Alex647N/CACACACACACACACACACA) was ordered from Integrated DNA Technologies (IDT) and stored at a stock concentration of $100 \mathrm{uM}$ at $-20^{\circ} \mathrm{C}$. The RNA FISH probe to detect ama1 mRNA was ordered from Stellaris (SMF-6011-1). After 6 hours, slides were washed twice, 10 min per wash, in FISH Wash Buffer (2X SSC, 10\% formamide, 0.1\% Tween-20). Samples were then washed for $5 \mathrm{~min}$ in 2 X SSC. Slides were sealed using $15 \mathrm{ul}$ of Slowfade Gold with DAPI. For experiments in which RNA FISH and immunofluorescence were combined, RNA FISH was first 125 performed as above. After the final 2X SSC wash, slides were washed once with PBST for 5 min, samples were incubated overnight at room temperature in a humid chamber with a 1:1000 dilution of GFP antibody (Abcam, ab290) in PBSTW. Slides were then washed three times, 10 min per wash, in PBSTW and incubated in a 1:100 dilution of Alexa Fluor 488 goat anti-rabbit in PBSTW 
for 2 hours at room temperature in a humid chamber. Slides were next washed three times, 10 min per wash, in PBSTW and then sealed with 15ul of Slowfade Gold with DAPI. All imaging was performed on an Axio Observer.Z1 fluorescent microscope (Zeiss) using the Plan-Apochromat 63 $\times / 1.4$ Oil DIC M27 objective. All image processing was done on $\mathrm{Fiji}^{12}$.

RNA-seq. Total RNA was extracted using TRIzol Reagent (Life Technologies, 15596018). RNA 135 quality (RIN) and quantity were assessed on the TapeStation 2200 (Agilent). Two rounds of mRNA purification were performed on 1ug total RNA using the Dynabeads mRNA DIRECT Kit (Invitrogen, 61011). First-strand cDNA was generated using the Superscript III First-Strand Synthesis System (Invitrogen, 18080051), followed by second-strand synthesis using DNA polymerase I (Invitrogen, 11917010). cDNA libraries were prepared using the Nextera XT DNA 140 Library Preparation Kit (Illumina, FC-131-1024). Libraries were sequenced on the Illumina NextSeq500 platform (Biopolymers Facility, HMS) and 75 bp paired-end reads were obtained.

RNA-seq analysis. Reads were trimmed to remove sequencing adapters and low-quality bases using Trim Galore version $\quad 0.4 .4$ dev

145 (https://www.bioinformatics.babraham.ac.uk/projects/trim galore/). Trimmed reads were then aligned to the $C$. elegans genome (UCSC ce11/WBcel235) using STAR version $2.7 .0 a^{13}$. Differential expression analysis of genes and repeat elements was performed using the TEtranscripts package in TEToolkit version $2.0 .3^{14}$. Gene annotations were obtained from Ensembl (WormBase release WS260) ${ }^{15}$. Repeat annotations were obtained from UCSC by 150 downloading the RepeatMasker (rmsk) table in the Table Browser program. The table was reformatted to a GTF file using the Perl script makeTEgtf.pl (http://labshare.cshl.edu/shares/mhammelllab/www-data/TEToolkit/TE GTF/). Features with an adjusted $p$ value of $<0.05$ and a log 2 fold change $>1.5$ were reported. 
CRISPR. The CRISPR strategy described previously ${ }^{16}$ was used to revert the missense mutation in rde-3(ne298) animals to wild-type and to tag the N-terminus of $r r f-1$ with ha::tagRFP. SapTrap cloning $^{17,18}$ and the selection-based CRISPR strategy described previously ${ }^{19}$ was used to introduce a gfp tag at the C-terminus of $c 38 d 9.2$, to tag rde-3 at the N-terminus with gfp::degron and to introduce $3 x f l a g:: r d e-3$ (with $2 \mathrm{~kb}$ upstream of the ATG and $2 \mathrm{~kb}$ downstream of the stop codon) at the LGII MosSCI site $t$ TTi560 20 into rde-3(ne3370) animals. All guide RNAs were designed using the guide RNA selection tool CRISPOR ${ }^{21}$.

Small RNA sequencing. rde-1(ne219); oma-1(zu405) animals were injected with an oma-1 pUG or pGC RNA in which the oma-1 sequence (the first $566 \mathrm{nt}$ of oma-1 mRNA) was modified to contain a SNP in exon 4 (ATTCATCCCG A>T TCATGGACCA). Injection mix was prepared as described above. For $\mathrm{P}_{0}$ analysis, $\sim 100$ rde-1(ne219) animals were injected per experiment. After recovering for 1-4 hours at room temperature, injected animals were collected for total RNA extraction. For $F_{1}$ analysis, $\sim 20$ rde-1(ne219) animals were injected per experiment. Injected animals recovered at $15^{\circ} \mathrm{C}$ for two days and were returned to room temperature. $\sim 500$ adult coinjection marker-expressing progeny of injected animals were collected for total RNA extraction. Small RNAs were size-selected, cloned and sequenced as described previously ${ }^{22}$. Note: the same SNP-containing oma-1 pUG RNA was used for Figure 5d, in which co-injection marker-expressing progeny of injected animals were picked and allowed to lay a brood that was collected for oma-1 pUG PCR analysis as described above.

Small RNA sequencing analysis. A custom Python script was used to select reads starting with the last 4 nucleotides of the 5' adaptor (either AGCG or CGTC). Cutadapt $1.14^{3}$ was then used to trim the 3' adaptor (CTGTAGGCACCATCAATAGATCGGAAGAGCAC) and the in-line portion of the 5' adaptor (AGCG and CGTC) (both with a minimum phred score = 20), allowing only

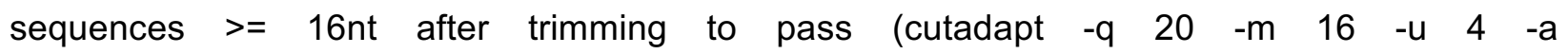


CTGTAGGCACCATCAATAGATCGGAAGAGCAC --discard-untrimmed). The quality of the trimming was assessed with FastQC $0.11 .5^{23}$. For downstream analysis, custom Python scripts were used to select reads that were $22 \mathrm{nt}$ in length and began with a $\mathrm{G}$ ( $22 \mathrm{G}$ siRNA reads). Tophat 2.1.1 $1^{24}$ was then used to map 22G siRNA reads to the $C$. elegans genome (WBcel235). Gene annotations were obtained from Ensembl ${ }^{15}$ (WormBase release WS269) and custom shell scripts were used to select protein-coding genes only. One mismatch was allowed to identify $22 \mathrm{G}$ siRNAs with SNPs. Using Samtools v0.1.19, only uniquely mapping sequences were retained. 22G RNA pileup figures were generated as follows: first, bam files generated from Tophat v2.1.1 ${ }^{24}$ were normalized by DeepTools $\mathrm{v} 3.0 .2^{25}$ based on counts per million and only antisense reads were 190 kept for further analysis (bamCoverage -bs 2 --normalizeUsing CPM -samFlagExclide 16). Then, the normalized antisense $22 \mathrm{G}$ small RNA sequences (bedGraph files) were visualized using Sushi $1.20 .0^{9}$ in R. The number of reads mapping antisense to each gene was calculated by featureCounts $1.6 .0^{26}$ (featureCounts -s 2 -a *.gtf -t exon -g gene_name ). All custom scripts used in this section are available at: https://github.com/Yuhan-Fei/pUG-analysis.

pUG RNA chromatography. Adult animals ( 1-2 full $10 \mathrm{~cm}$ plates per experiment) were frozen in liquid nitrogen as small droplets and ground into powder with a mortar and pestle. Powder was dissolved in lysis buffer (5mM HEPES- $\mathrm{NaOH}(\mathrm{pH} 7.5), 50 \mathrm{mM} \mathrm{NaCl}, 5 \mathrm{mM} \mathrm{MgCl} 2,0.5 \mathrm{mM}$ EDTA (pH8.0), 5\% glycerol, 0.25\% Triton X-100, 0.5mM DTT, 1mM PMSF, 1 tablet of cOmplete 200 protease inhibitor (Roche, 11697498001)) and rotated for 30 minutes at $4^{\circ} \mathrm{C}$. The resulting lysate was centrifuged at top speed for $10 \mathrm{~min}$ at $4^{\circ} \mathrm{C}$. Supernatant was distributed evenly among experiments, and RNaseOUT recombinant ribonuclease inhibitor (Invitrogen, 10777019) was added to lysate (1ul per 100ul lysate). For each experiment, 160pmol of biotinylated RNA was conjugated to 400ug Dynabeads MyOne Streptavidin beads (Invitrogen, 65001) as per 205 manufacturer's instructions. Beads were added to lysates and rotated at room temperature for 1 hour. Beads were separated from supernatant on a magnetic rack, and the supernatant was 
210 chilled on ice ("pull-down" fraction).

Gel electrophoresis and Western blot. "Pull-down" and "sup" fractions were loaded into 4-15\% Mini-PROTEAN TGX Precast protein gels (Biorad, 4561086) and run in Tris-glycine running buffer (25mM Tris, $192 \mathrm{mM}$ glycine, $0.1 \%$ SDS). Proteins were then transferred to nitrocellulose 215 membrane (BioRad) at 100V for 1 hour in electrotransfer buffer (50mM Tris, 40mM glycine, 9\% methanol, $0.2 \%$ SDS). Blotted membranes were blocked with $5 \%$ milk in PBST (phosphatebuffered saline, $1.0 \%$ Tween-20) for 1 hour at room temperature and probed with primary antibody (1:1000 HA-Tag Rabbit mAb, Cell Signaling, \#3724, in 5\% milk) overnight at $4^{\circ} \mathrm{C}$. After washing with PBST 3 times, membrane was probed with secondary antibody (1:10,000 IRDye 800CW 220 Goat anti-Rabbit IgG, LI-COR, 926-32211, in 5\% milk) for 1 hour at room temperature. Membrane was washed with PBST 3 times before imaging using Odyssey Fc Dual-Mode Imaging System (LI-COR).

Heterozygous Experiment. Embryos were obtained via hypochlorite treatment of wild-type 225 gravid adult hermaphrodites and dropped onto plates seeded with HT115 bacteria expressing dsRNA targeting oma-1. $L_{4}$ hermaphrodites were then transferred, along with rde-3(ne298) males, onto "mating plates" seeded with 25ul of oma-1 dsRNA-expressing bacteria. Once hermaphrodites were adults, they were singled onto NGM plates seeded with OP50 and allowed to lay a brood. 12-15 $F_{1} s$ were singled from 3 independently mated hermaphrodites and 230 genotyped to ensure that they were heterozygous for rde-3(ne298). To obtain $F_{3}$ animals, 12-15 $\mathrm{F}_{2} \mathrm{~S}$ per $\mathrm{F}_{1}$ were singled to $15^{\circ} \mathrm{C}$ (so as to avoid embryonic arrest due to temperature) and allowed to lay a brood. F2s were then single worm genotyped to identify $r d e-3(+)$ and $r d e(n e 298)$ 
bioRxiv preprint doi: https://doi.org/10.1101/2019.12.31.891960; this version posted December 31, 2019. The copyright holder for this preprint

(which was not certified by peer review) is the author/funder, who has granted bioRxiv a license to display the preprint in perpetuity. It is made available under aCC-BY-NC-ND 4.0 International license.

homozygous animals. Then, \% embryonic arrest was calculated by pooling $5 L_{4}$ stage $F_{3}$ animals per $\mathrm{F}_{2}$ at $20^{\circ} \mathrm{C}$ until they had laid a brood of 50-200 progeny and counting the \# of embryos that

235 were laid vs. hatched on the following day. $r d e-3(+)$ and $r d e(n e 298)$ homozygous $F_{3}$ broods were pooled for all plates that were derived from the same $P_{0}$ and pUG PCR was performed as described above. 


\section{References for methods}

1. Brenner, S. The genetics of Caenorhabditis elegans. Genetics 77, 71-94 (1974).

2. Smith, T., Heger, A. \& Sudbery, I. UMI-tools: modeling sequencing errors in Unique Molecular Identifiers to improve quantification accuracy. Genome Res. 27, 491-499 (2017).

3. Martin, M. Cutadapt removes adapter sequences from high-throughput sequencing reads. EMBnet.journal 17, 10-12 (2011).

4. Dobin, A. et al. STAR: ultrafast universal RNA-seq aligner. Bioinformatics 29, 15-21 (2013).

5. Li, H. et al. The Sequence Alignment/Map format and SAMtools. Bioinformatics 25, 2078-2079 (2009).

6. Quinlan, A. R. \& Hall, I. M. BEDTools: a flexible suite of utilities for comparing genomic features. Bioinformatics 26, 841-842 (2010).

7. RStudio Team. RStudio: Integrated Development for R. (2016).

8. Pagès, H., Aboyoun, P., Gentleman, R. \& DebRoy, S. Biostrings: Efficient manipulation of biological strings. $R$ package version 20.50 .2 2, (2017).

9. Phanstiel, D. H., Boyle, A. P., Araya, C. L. \& Snyder, M. P. Sushi.R: flexible, quantitative and integrative genomic visualizations for publication-quality multi-panel figures. Bioinformatics 30, 2808-2810 (2014).

10. Wagih, O. ggseqlogo: a versatile R package for drawing sequence logos. Bioinformatics $\mathbf{3 3}$, 3645-3647 (2017).

11. Alcazar, R. M., Lin, R. \& Fire, A. Z. Transmission dynamics of heritable silencing induced by double-stranded RNA in Caenorhabditis elegans. Genetics 180, 1275-1288 (2008).

12. Schindelin, J. et al. Fiji: an open-source platform for biological-image analysis. Nat. Methods 9, 676-682 (2012).

13. Dobin, A. et al. STAR: ultrafast universal RNA-seq aligner. Bioinformatics29, 15--21. 
(2013).

14. Jin, Y., Tam, O. H., Paniagua, E. \& Hammell, M. TEtranscripts: a package for including transposable elements in differential expression analysis of RNA-seq datasets.

Bioinformatics 31, 3593-3599 (2015).

15. Cunningham, F. et al. Ensembl 2019. Nucleic Acids Res. 47, D745-D751 (2019).

16. Wan, G. et al. Spatiotemporal regulation of liquid-like condensates in epigenetic inheritance. Nature vol. 557 679-683 (2018).

17. Schwartz, M. L. \& Jorgensen, E. M. SapTrap, a Toolkit for High-Throughput CRISPR/Cas9 Gene Modification in Caenorhabditis elegans. Genetics vol. 202 1277-1288 (2016).

18. Dickinson, D. J., Slabodnick, M. M., Chen, A. H. \& Goldstein, B. SapTrap assembly of repair templates for Cas9-triggered homologous recombination with a self-excising cassette. MicroPublication Biol. . Dataset 10, W2KTON (2018).

19. Dickinson, D. J., Pani, A. M., Heppert, J. K., Higgins, C. D. \& Goldstein, B. Streamlined Genome Engineering with a Self-Excising Drug Selection Cassette. Genetics 200, 1035-1049 (2015).

20. Frøkjaer-Jensen, C. et al. Single-copy insertion of transgenes in Caenorhabditis elegans. Nat. Genet. 40, 1375-1383 (2008).

21. Haeussler, M. et al. Evaluation of off-target and on-target scoring algorithms and integration into the guide RNA selection tool CRISPOR. Genome Biol. 17, 148 (2016).

22. Dodson, A. E. \& Kennedy, S. Germ Granules Coordinate RNA-Based Epigenetic Inheritance Pathways. Dev. Cell 50, 704-715.e4 (2019).

23. Andrews, S. \& Others. FastQC: a quality control tool for high throughput sequence data. (2010).

24. Trapnell, C., Pachter, L. \& Salzberg, S. L. TopHat: discovering splice junctions with 
bioRxiv preprint doi: https://doi.org/10.1101/2019.12.31.891960; this version posted December 31, 2019. The copyright holder for this preprint

(which was not certified by peer review) is the author/funder, who has granted bioRxiv a license to display the preprint in perpetuity. It is made available under aCC-BY-NC-ND 4.0 International license.

RNA-Seq. Bioinformatics 25, 1105-1111 (2009).

25. Ramírez, F., Dündar, F., Diehl, S., Grüning, B. A. \& Manke, T. deepTools: a flexible platform for exploring deep-sequencing data. Nucleic Acids Res. 42, W187-91 (2014).

26. Liao, Y., Smyth, G. K. \& Shi, W. featureCounts: an efficient general purpose program for assigning sequence reads to genomic features. Bioinformatics 30, 923-930 (2014). 


\section{Acknowledgements}

We thank members of the Kennedy, Butcher and Wickens labs for helpful discussions; the Biopolymers Facility at HMS for Illumina sequencing; and the Dana-Farber/Harvard Cancer Center DNA Resource Core for Sanger sequencing. Some strains were provided by the Caenorhabditis Genetics Center (CGC), which is funded by the NIH Office of Research Infrastructure Programs (P40 OD010440). Some strains were provided by the Mitani laboratory through the National BioResource Project (Tokyo, Japan), which is part of the International C. elegans Gene Knockout Consortium.

\section{Author contributions}

A.S. contributed to Figs. 1a-f, 3a-g, 5a, 5c-g; Extended Data Figs. 1a-c; 4a-c; 6; 8a, 8c; 9a-c; and Supplementary Tables S1, S2, S4. J.Y. contributed to Figs. 2a-c, 3h, 4a-c, 5b; Extended Data Figs. 2a-b, 3a-b; 5, 7, 8b; Supplementary TableS S3, S4. D.J.P., J.G. and J.G.S. contributed to Extended Data Fig. 4 and Supplementary Table S2. A.E.D. contributed to Figs. 1e-f; Extended Data Fig. 9b; and Supplementary Table S1. Y.F. contributed to Fig. 4c; Extended Data Figs. 5, 8b; and Supplementary Table S3. A.S., M.W. and S.K. conceived the project. S.K. supervised the project. A.S. and S.K. wrote the manuscript.

\section{Competing interests}

The authors declare no competing interests. 
bioRxiv preprint doi: https://doi.org/10.1101/2019.12.31.891960; this version posted December 31, 2019. The copyright holder for this preprint (which was not certified by peer review) is the author/funder, who has granted bioRxiv a license to display the preprint in perpetuity. It is made available under aCC-BY-NC-ND 4.0 International license.

a

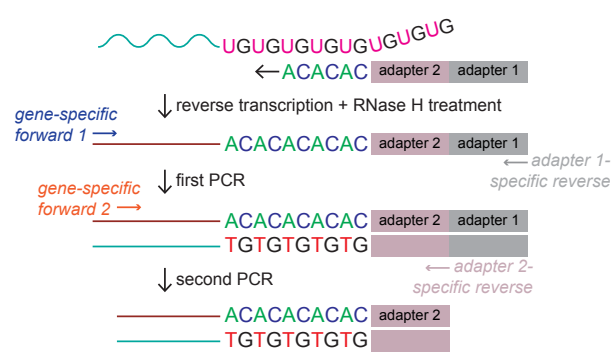

b

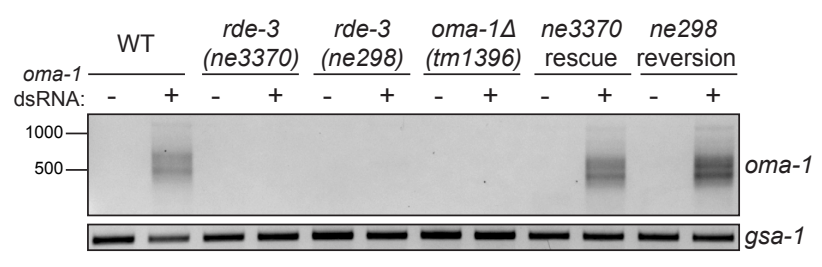

C

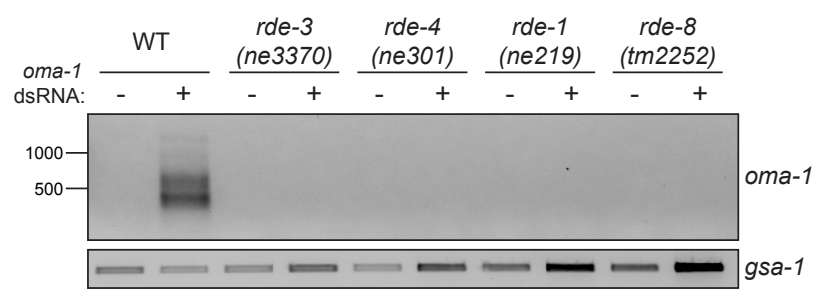

d

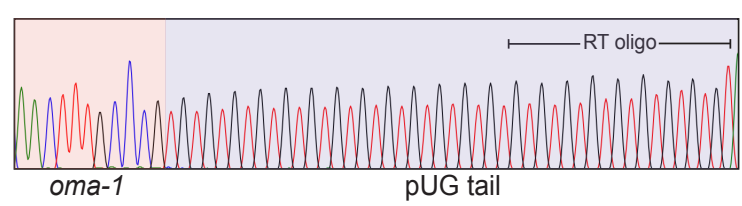

e

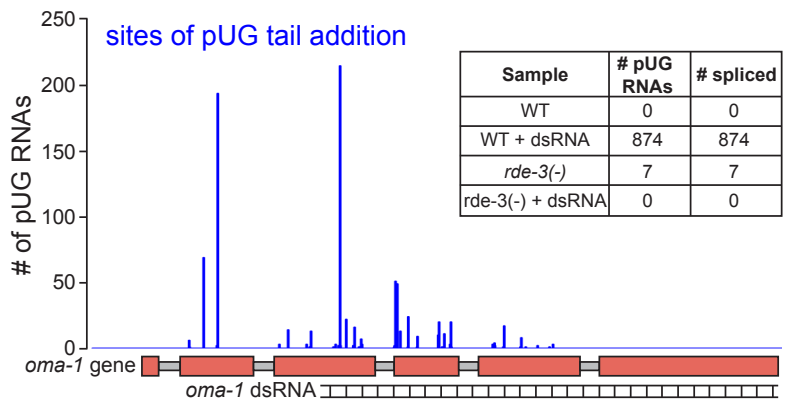

f

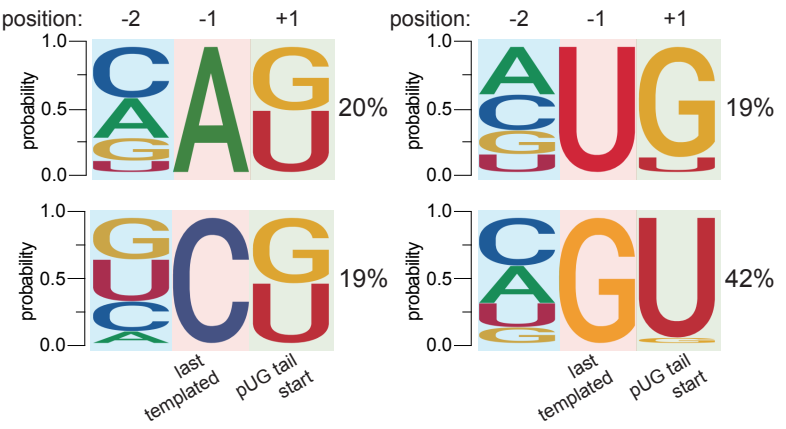


bioRxiv preprint doi: https://doi.org/10.1101/2019.12.31.891960; this version posted December 31, 2019. The copyright holder for this preprint (which was not certified by peer review) is the author/funder, who has granted bioRxiv a license to display the preprint in perpetuity. It is made available under aCC-BY-NC-ND 4.0 International license.

a

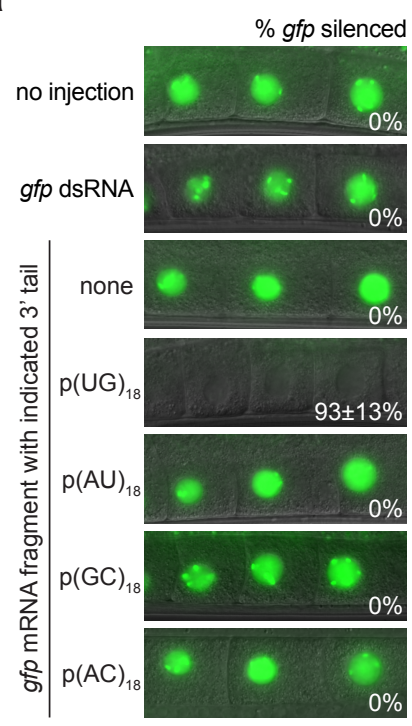

b

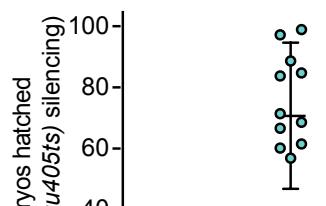

$20-$

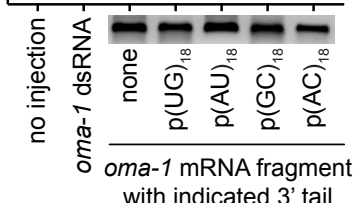

C

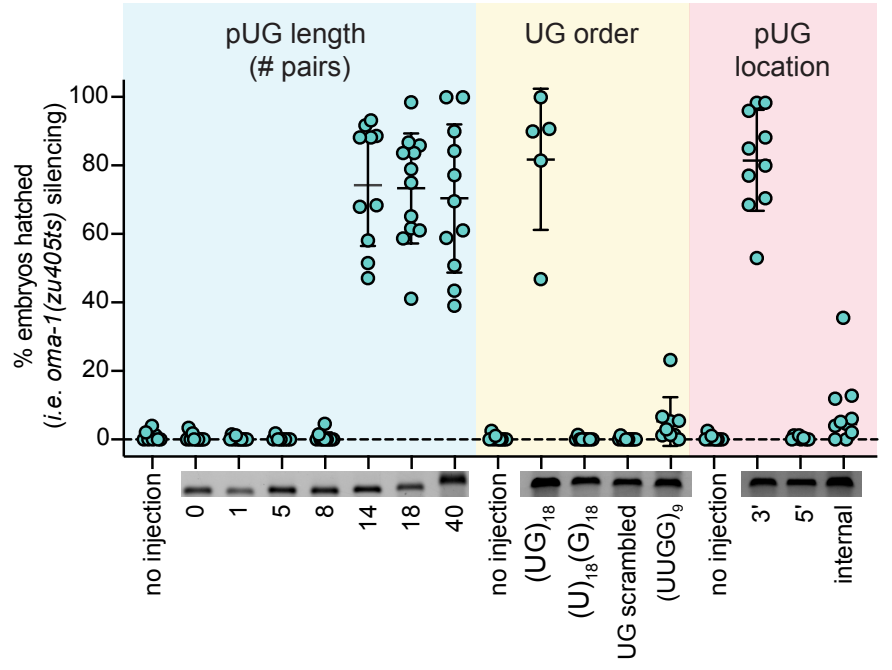

Figure 2 
bioRxiv preprint doi: https://doi.org/10.1101/2019.12.31.891960; this version posted December 31, 2019. The copyright holder for this preprint (which was not certified by peer review) is the author/funder, who has granted bioRxiv a license to display the preprint in perpetuity. It is made available under aCC-BY-NC-ND 4.0 International license.

a

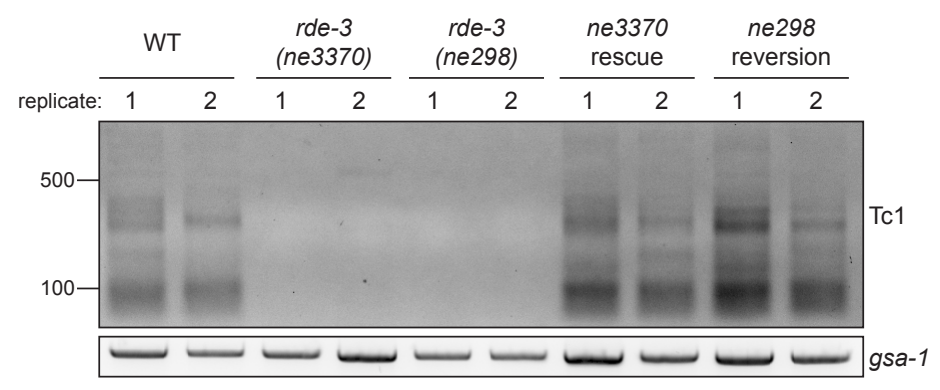

d

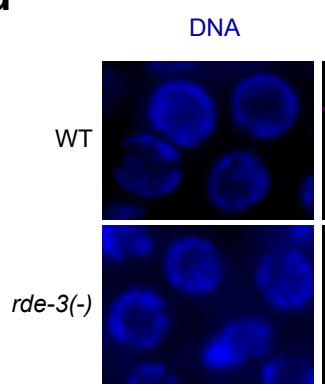

pUG RNAs

ama-1 mRNA

DNA + pUG RNAs

merge
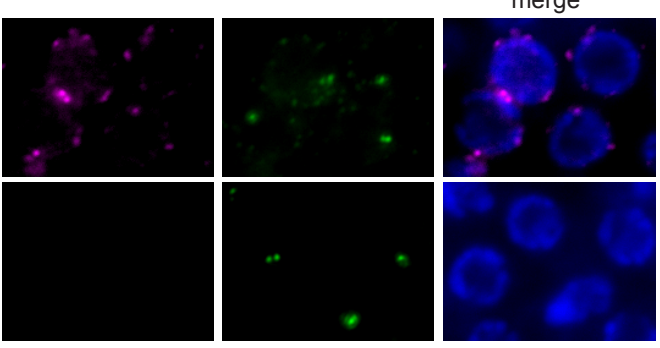

f

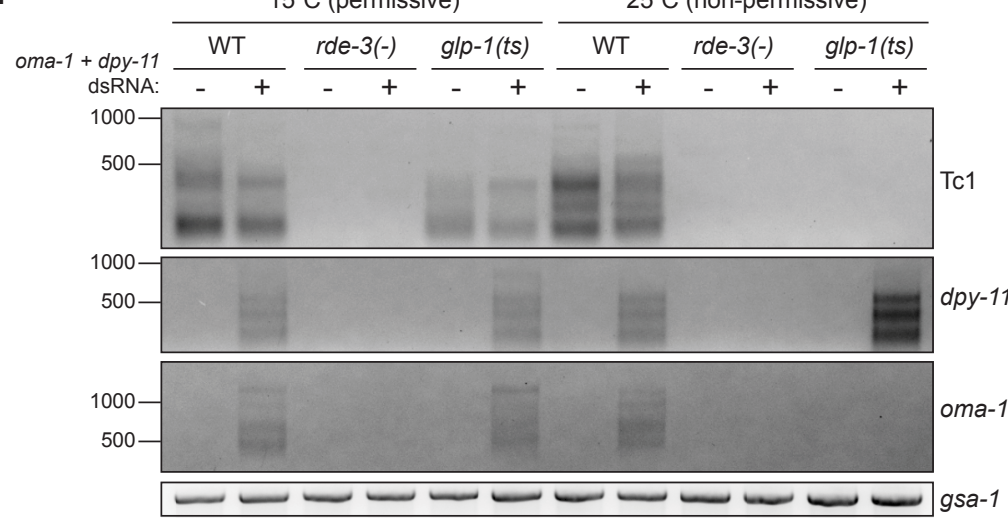

b

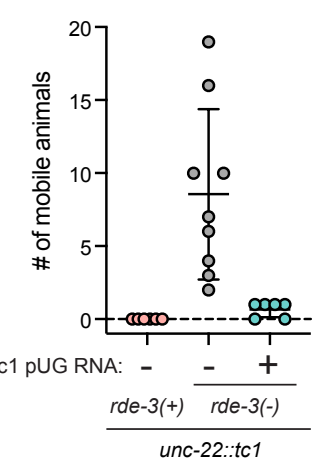

e

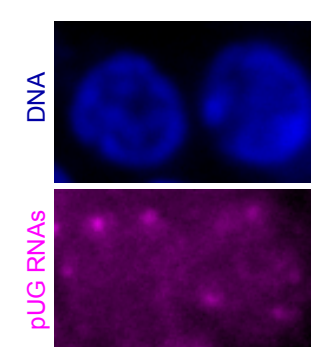

h
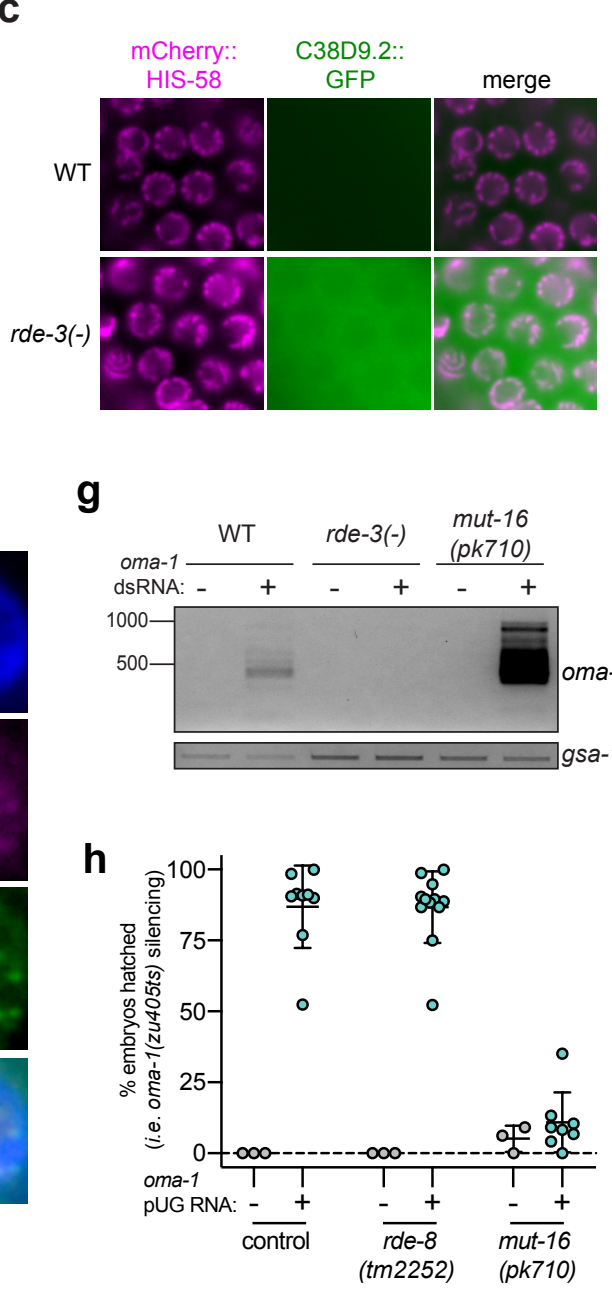

g
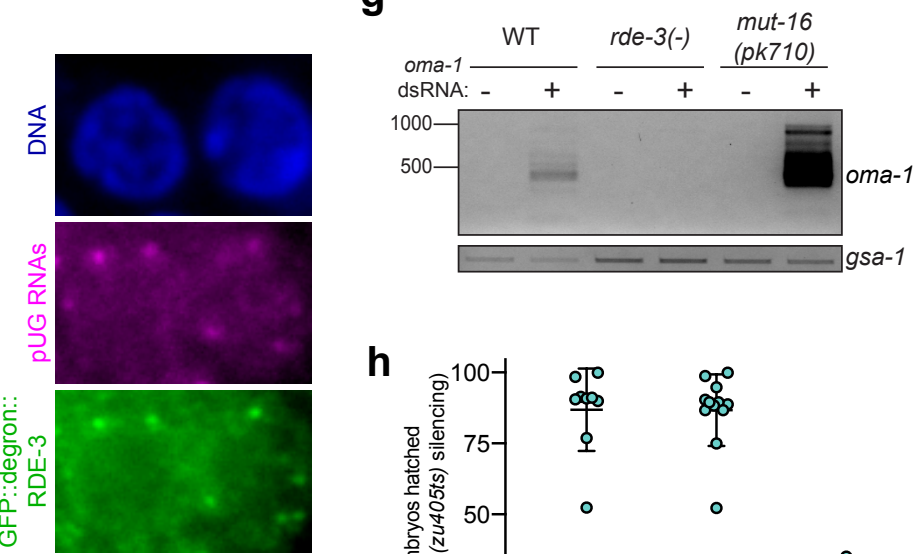

ฮั

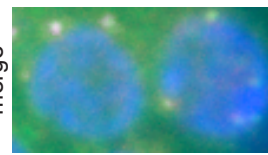


bioRxiv preprint doi: https://doi.org/10.1101/2019.12.31.891960; this version posted December 31, 2019. The copyright holder for this preprint (which was not certified by peer review) is the author/funder, who has granted bioRxiv a license to display the preprint in perpetuity. It is made available under aCC-BY-NC-ND 4.0 International license.

a

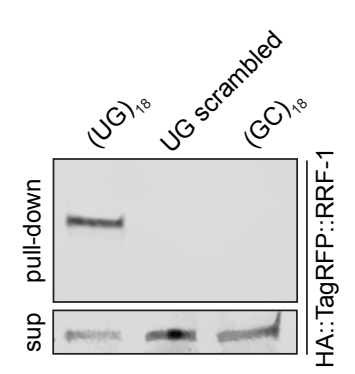

b

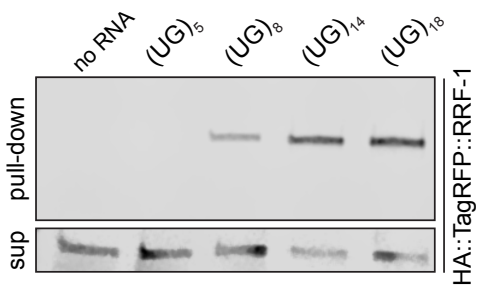

C

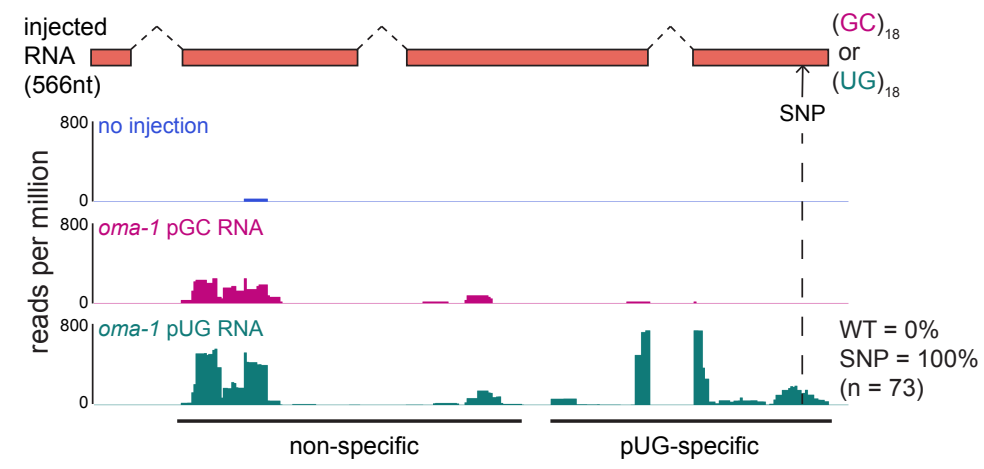

Figure 4 
bioRxiv preprint doi: https://doi.org/10.1101/2019.12.31.891960; this version posted December 31, 2019. The copyright holder for this preprint (which was not certified by peer review) is the author/funder, who has granted bioRxiv a license to display the preprint in perpetuity. It is made available under aCC-BY-NC-ND 4.0 International license.

a

b
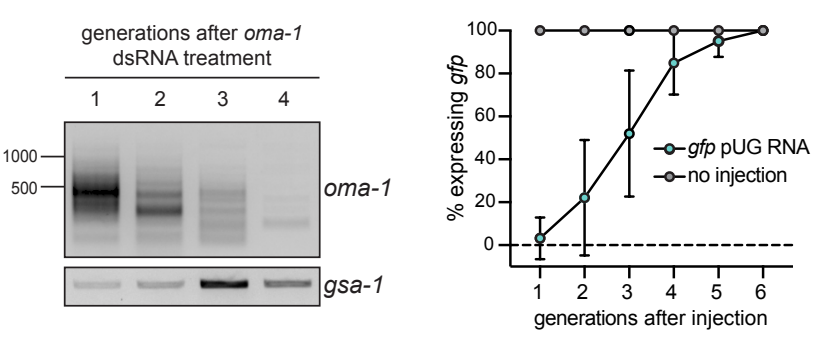

C

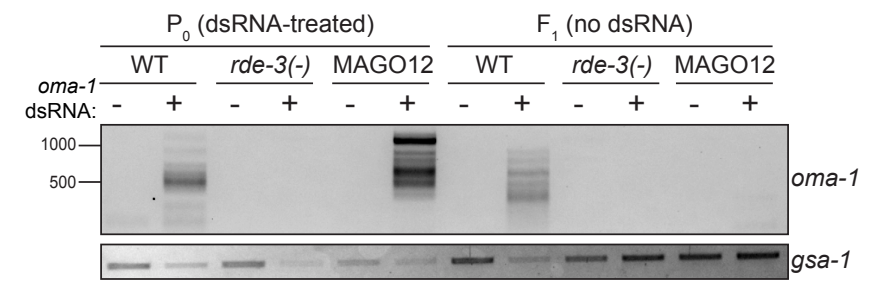

d

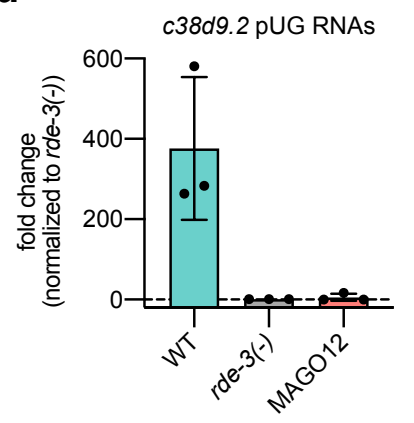

Tc1 pUG RNAs e

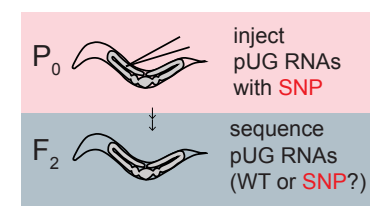

f

\begin{tabular}{|c|c|c|}
\hline Replicate & $\begin{array}{c}\text { \# pUG RNAs } \\
\text { with SNP }\end{array}$ & $\begin{array}{c}\text { W W pUG } \\
\text { RNAs }\end{array}$ \\
\hline 1 & $0 / 4$ & $4 / 4$ \\
\hline 2 & $0 / 4$ & $4 / 4$ \\
\hline 3 & $0 / 4$ & $4 / 4$ \\
\hline
\end{tabular}

g
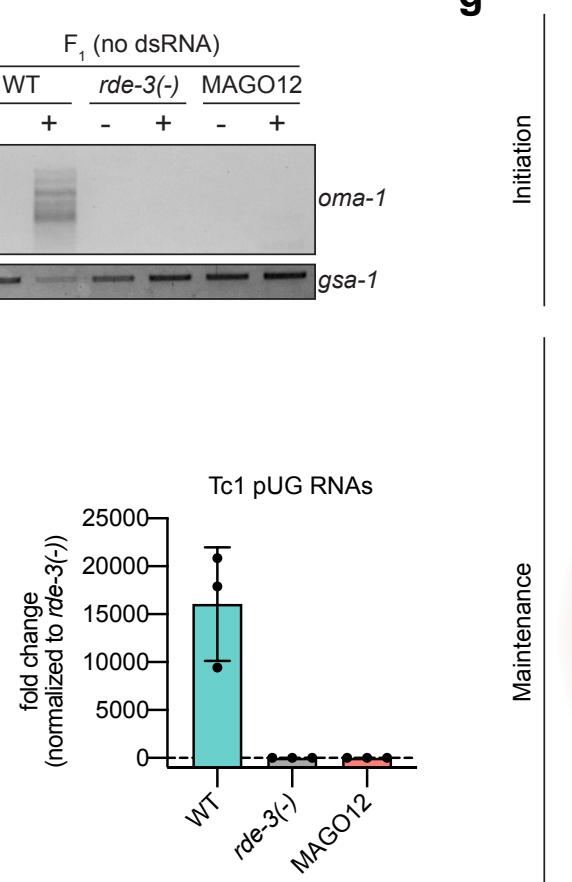

Figure 5 
bioRxiv preprint doi: https://doi.org/10.1101/2019.12.31.891960; this version posted December 31, 2019. The copyright holder for this preprint (which was not certified by peer review) is the author/funder, who has granted bioRxiv a license to display the preprint in perpetuity. It is made available under aCC-BY-NC-ND 4.0 International license.

a

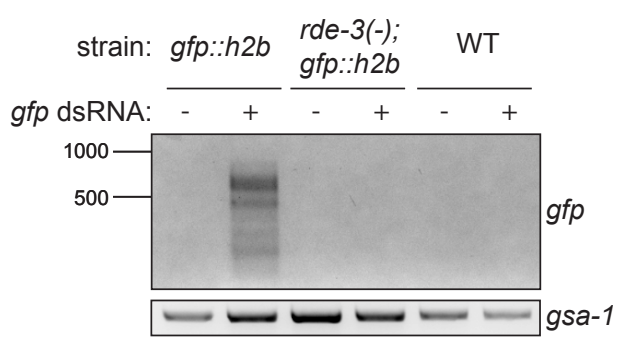

b
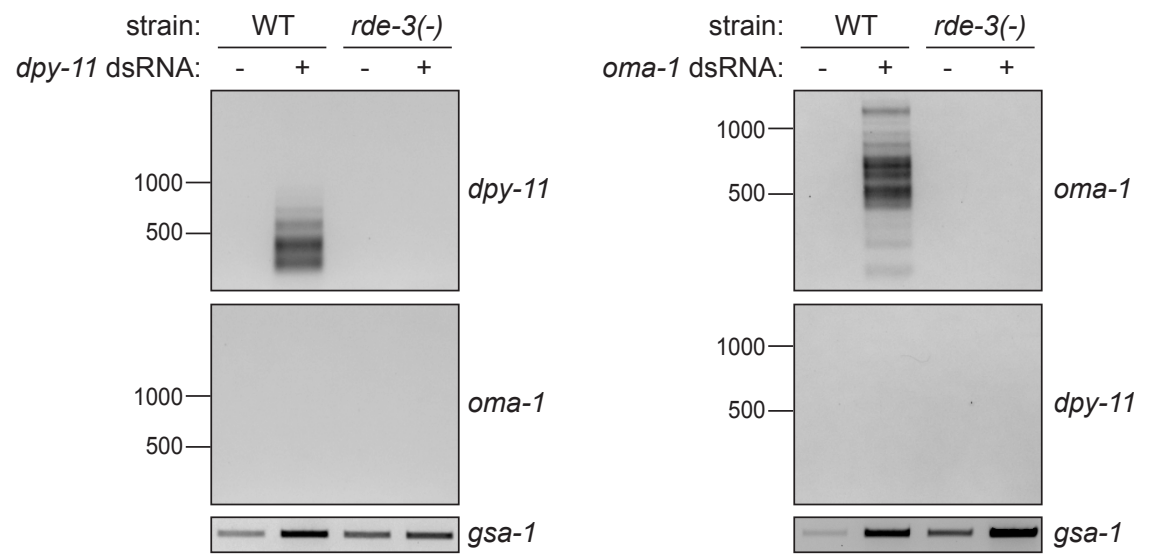

Extended Data Figure 1 
bioRxiv preprint doi: https://doi.org/10.1101/2019.12.31.891960; this version posted December 31, 2019. The copyright holder for this preprint (which was not certified by peer review) is the author/funder, who has granted bioRxiv a license to display the preprint in perpetuity. It is made available under aCC-BY-NC-ND 4.0 International license.

a

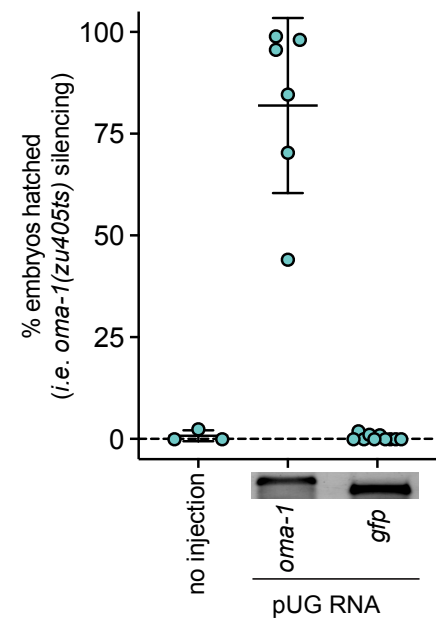

b

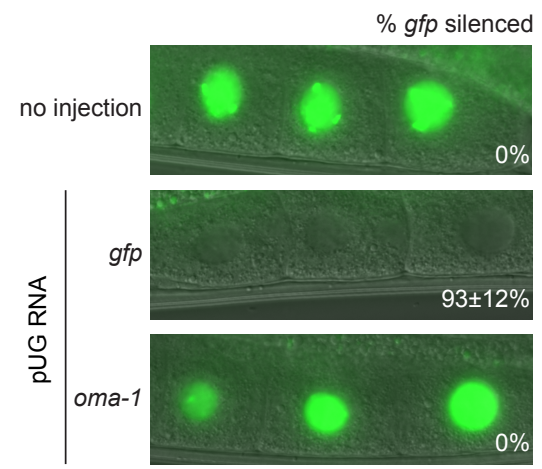

Extended Data Figure 2 
bioRxiv preprint doi: https://doi.org/10.1101/2019.12 31.891960; this version posted December 31, 2019. The copyright holder for this preprint (which was not certified by peer review) is the author/funder, who has granted bioRxiv a license to display the preprint in perpetuity. It is made available under aCC-BY-NC-ND 4.0 International license.

a

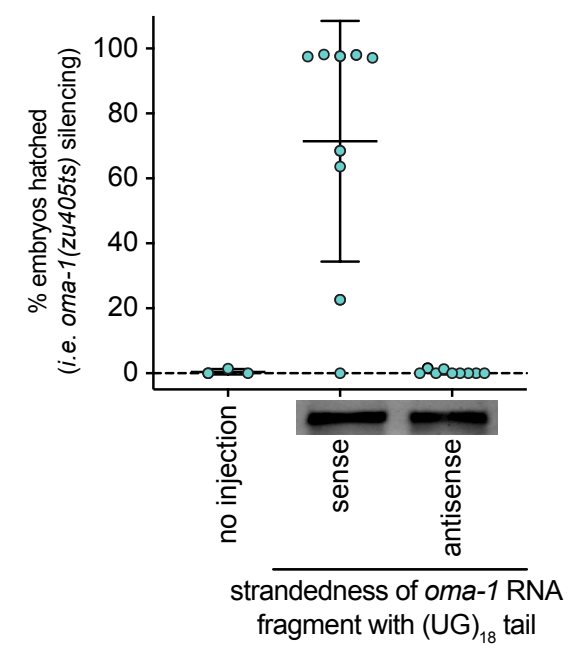

b

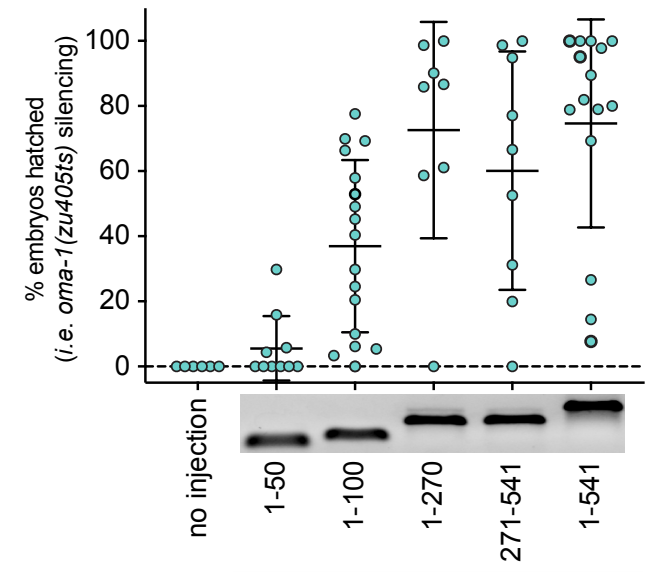

nucleotides of oma-1 mRNA

with (UG) ${ }_{18}$ tail 
bioRxiv preprint doi: https://doi.org/10.1101/2019.12.31.891960; this version posted December 31, 2019. The copyright holder for this preprint (which was not certified by peer review) is the author/funder, who has granted bioRxiv a license to display the preprint in perpetuity. It is made available under aCC-BY-NC-ND 4.0 International license.

a

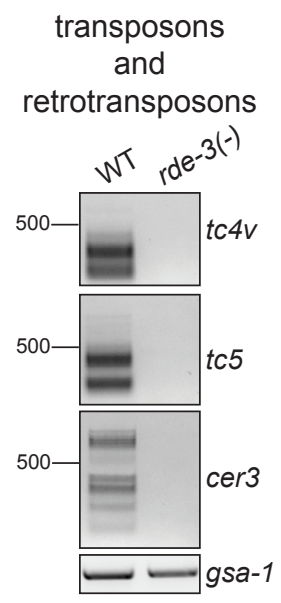

b

RDE-3-

regulated

mRNAs

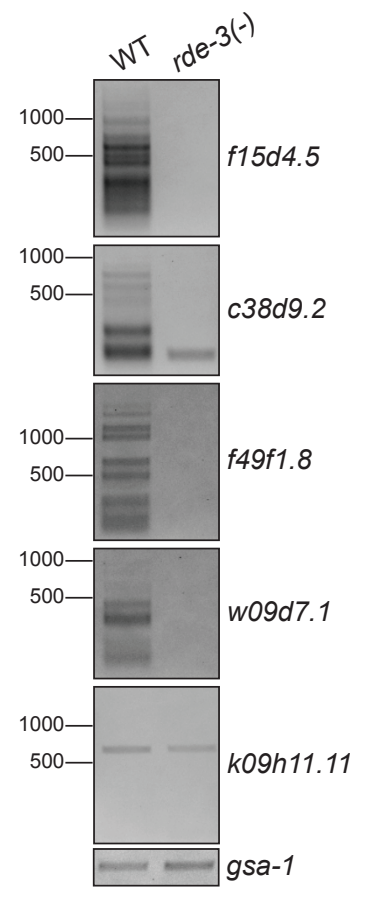

C

Negative controls:

RDE-3-independent mRNAs

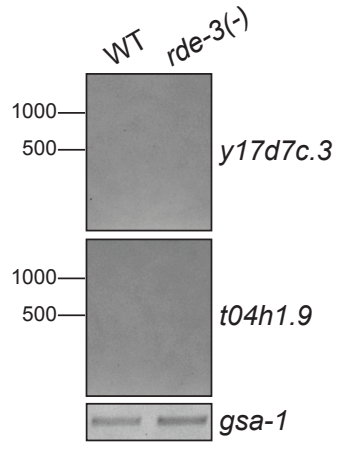


bioRxiv preprint doi: https://doi.org/10.1101/2019.12.31.891960; this version posted December 31, 2019. The copyright holder for this preprint (which was not certified by peer review) is the author/funder, who has granted bioRxiv a license to display the preprint in perpetuity. It is made available under aCC-BY-NC-ND 4.0 International license.

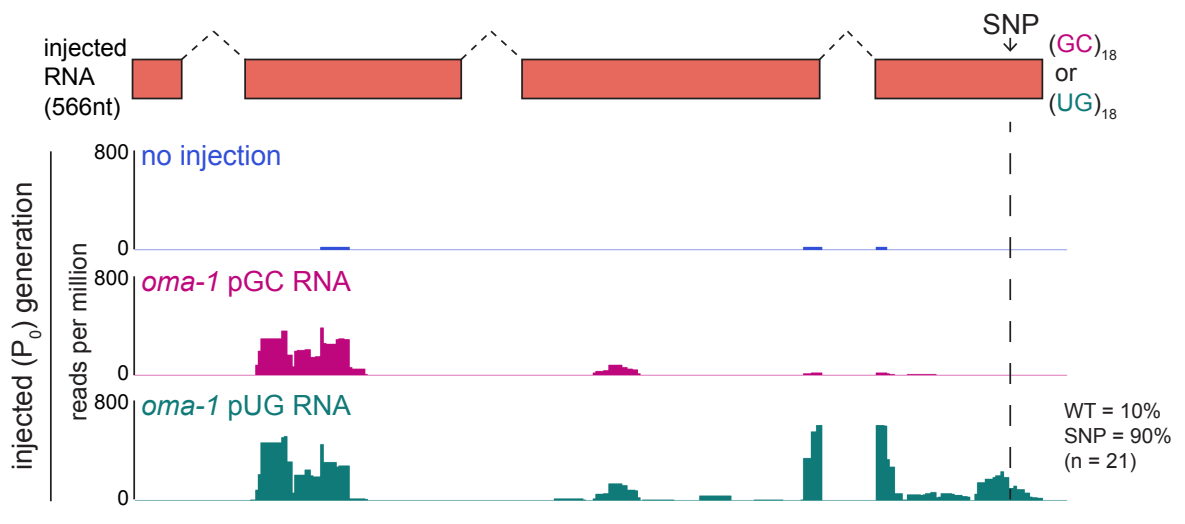

Extended Data Figure 5 
bioRxiv preprint doi: https://doi.org/10.1101/2019.12.31.891960; this version posted December 31, 2019. The copyright holder for this preprint (which was not certified by peer review) is the author/funder, who has granted bioRxiv a license to display the preprint in perpetuity. It is made available under aCC-BY-NC-ND 4.0 International license.

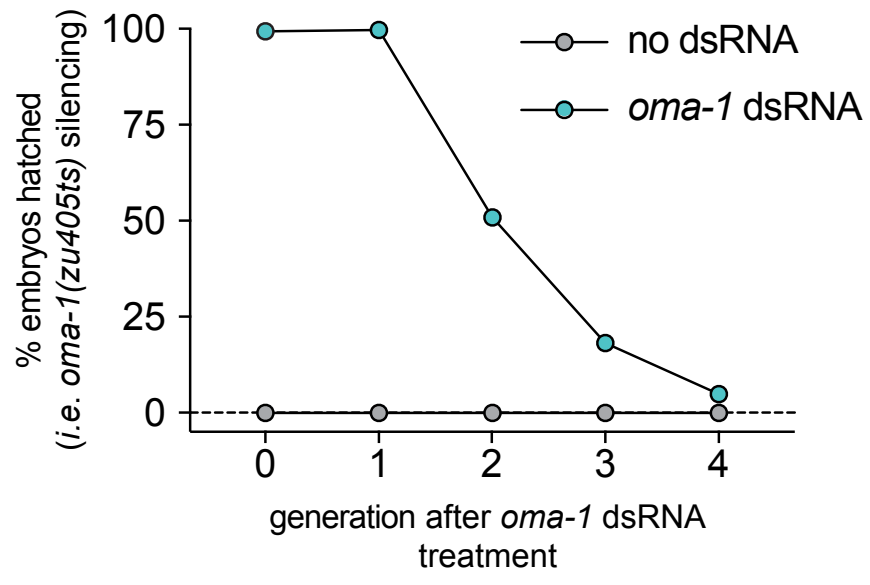

Extended Data Figure 6 
bioRxiv preprint doi: https://doi.org/10.1101/2019.12.31.891960; this version posted December 31, 2019. The copyright holder for this preprint (which was not certified by peer review) is the author/funder, who has granted bioRxiv a license to display the preprint in perpetuity. It is made available under aCC-BY-NC-ND 4.0 International license.

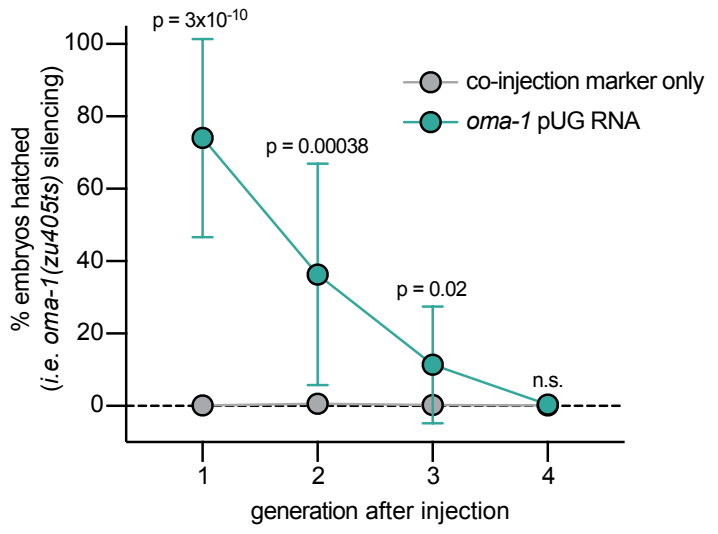

Extended Data Figure 7 
bioRxiv preprint doi: $\mathrm{https}$ //doi.org/10.1101/2019.12.31.891960; this version posted December 31, 2019. The copyright holder for this preprint (which was not certified by peer review) is the author/funder, who has granted bioRxiv a license to display the preprint in perpetuity. It is made available under aCC-BY-NC-ND 4.0 International license.

a

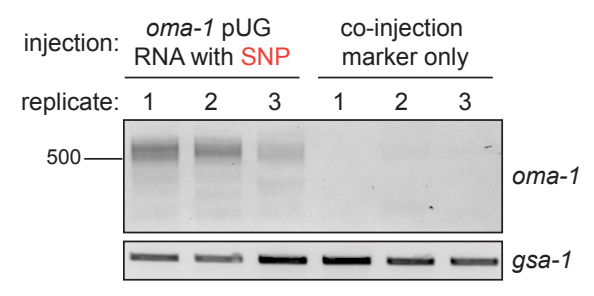

b

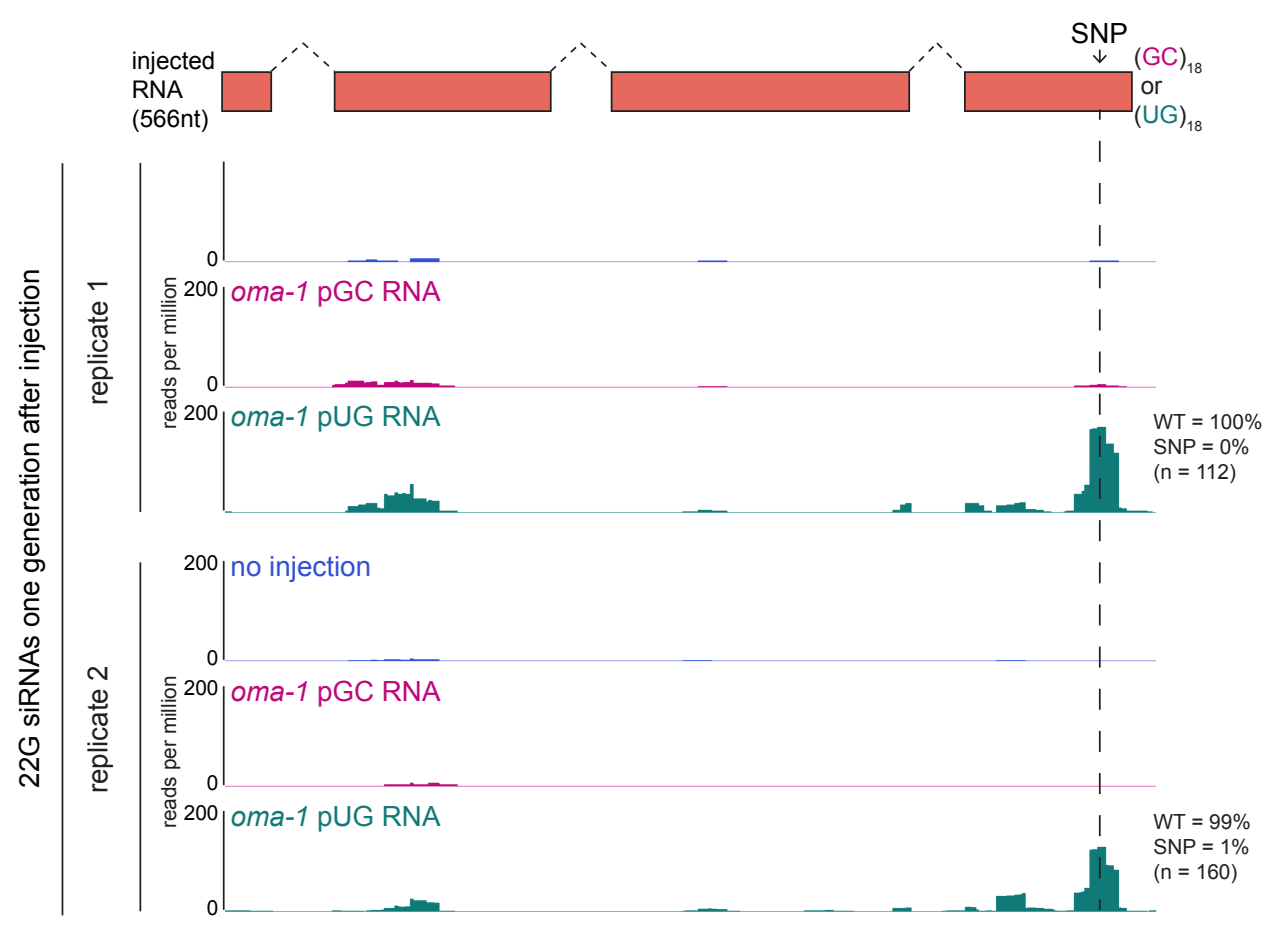

C

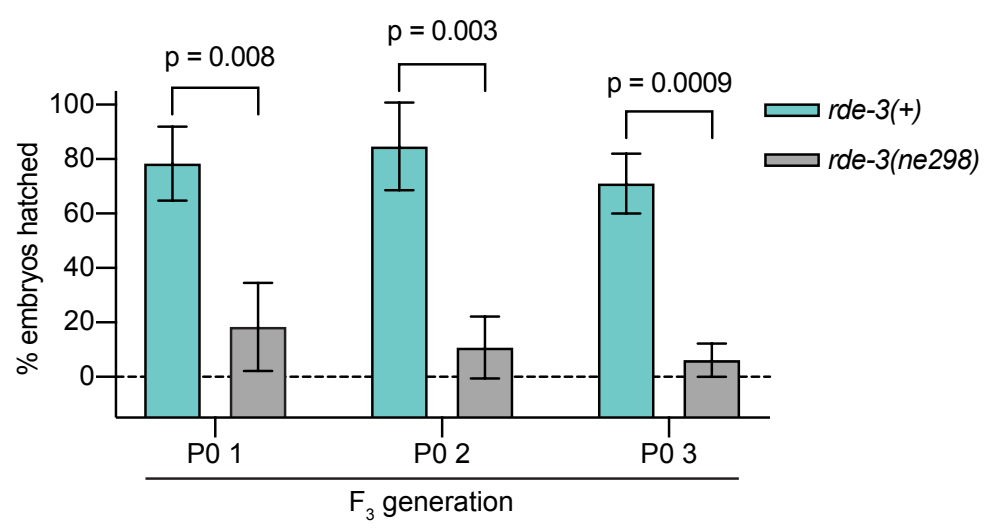

Extended Data Figure 8 
bioRxiv preprint doi: $\mathrm{https}$ //doi.org/10.1101/2019.12.31.891960; this version posted December 31, 2019. The copyright holder for this preprint (which was not certified by peer review) is the author/funder, who has granted bioRxiv a license to display the preprint in perpetuity. It is made available under aCC-BY-NC-ND 4.0 International license.

$\mathbf{a}$

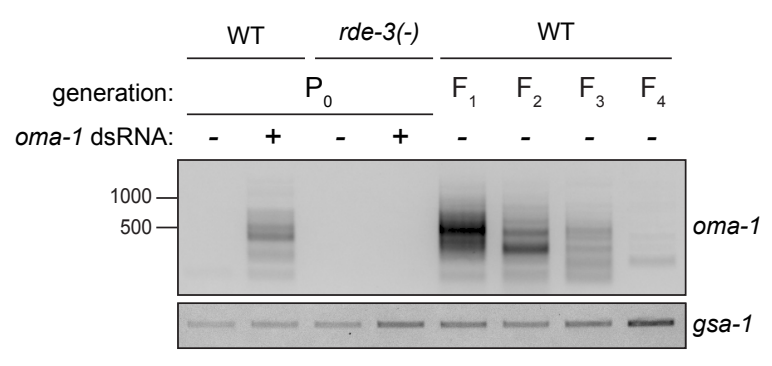

b

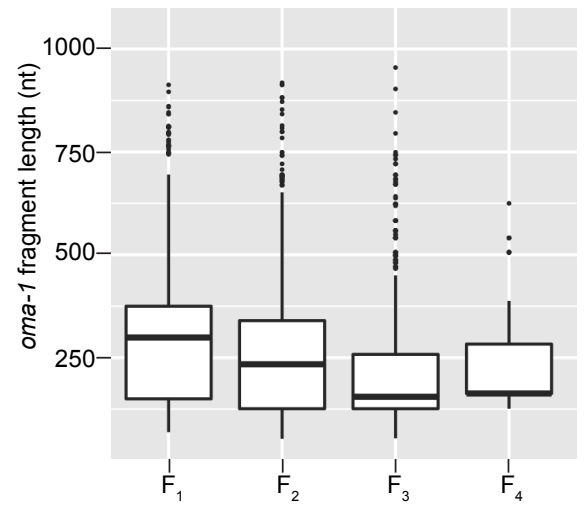

C

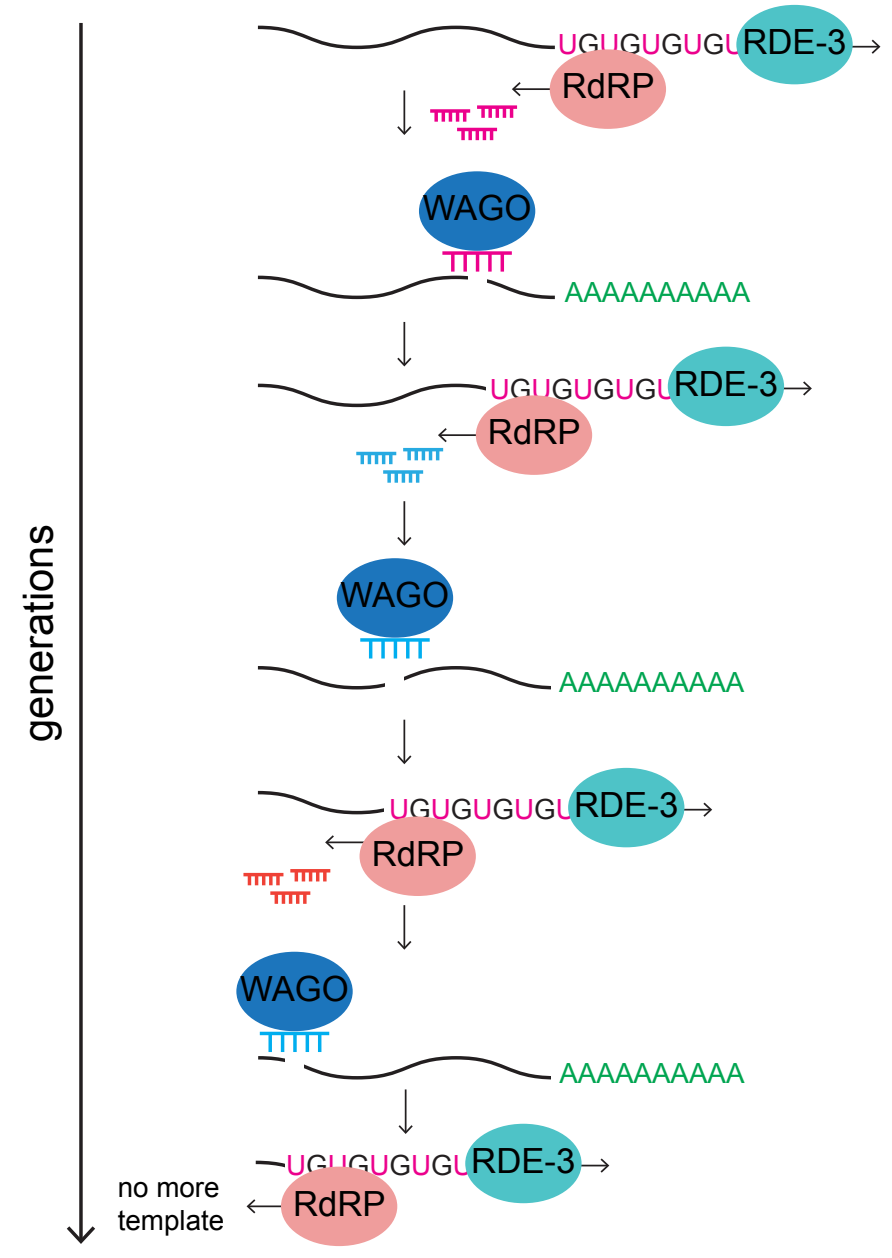

